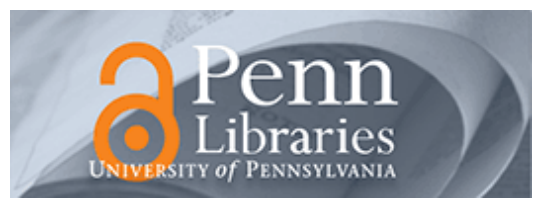

University of Pennsylvania

ScholarlyCommons

Operations, Information and Decisions Papers

Wharton Faculty Research

$7-2002$

\title{
Swift Neighbors and Persistent Strangers: A Cross-Cultural Investigation of Trust and Reciprocity in Social Exchange
}

Nancy. R. Buchan

Rachel Croson

University of Pennsylvania

Robyn. M. Dawes

Follow this and additional works at: https://repository.upenn.edu/oid_papers

Part of the Biology Commons, Civic and Community Engagement Commons, and the Other Sociology Commons

\section{Recommended Citation}

Buchan, N. R., Croson, R., \& Dawes, R. M. (2002). Swift Neighbors and Persistent Strangers: A Cross-Cultural Investigation of Trust and Reciprocity in Social Exchange. American Journal of Sociology, 108 (1), 168-206. http://dx.doi.org/10.1086/344546

This paper is posted at ScholarlyCommons. https://repository.upenn.edu/oid_papers/246

For more information, please contact repository@pobox.upenn.edu. 


\title{
Swift Neighbors and Persistent Strangers: A Cross-Cultural Investigation of Trust and Reciprocity in Social Exchange
}

\author{
Abstract \\ In four countries, levels of trust and reciprocity in direct-reciprocal exchange are compared with those in \\ network-generalized exchanges among experimentally manipulated groups' members (neighbors) or \\ random experimental participants (strangers). Results show that cooperation decreases as social \\ distance increases; and, that identical network-generalized exchanges generate different amounts of \\ trusting behavior due solely to manipulated social identity between the actors. This study demonstrates \\ the interaction of culture and social identity on the propensity to trust and reciprocate and also reveals \\ differing relationships between trust and reciprocation in each of the four countries, bringing into \\ question the theoretical relationship between these cooperative behaviors. \\ Disciplines \\ Biology | Civic and Community Engagement | Other Sociology
}




\title{
Swift Neighbors and Persistent Strangers: A Cross-Cultural Investigation of Trust and Reciprocity in Social Exchange ${ }^{1}$
}

\author{
Nancy R. Buchan \\ University of Wisconsin, Madison \\ Rachel T. A. Croson \\ University of Pennsylvania \\ Robyn M. Dawes \\ Carnegie Mellon University
}

\begin{abstract}
In four countries, levels of trust and reciprocity in direct-reciprocal exchange are compared with those in network-generalized exchanges among experimentally manipulated groups' members (neighbors) or random experimental participants (strangers). Results show that cooperation decreases as social distance increases; and, that identical network-generalized exchanges generate different amounts of trusting behavior due solely to manipulated social identity between the actors. This study demonstrates the interaction of culture and social identity on the propensity to trust and reciprocate and also reveals differing relationships between trust and reciprocation in each of the four countries, bringing into question the theoretical relationship between these cooperative behaviors.
\end{abstract}

In a recent issue of Science, biologists hailed trust and reciprocity as the "basis of all human systems of morality" (Nowak and Sigmund 2000).

\footnotetext{
${ }^{1}$ We thank the participants at the International Conference on Social Dilemmas, the Economic Science Association, the Society for Judgment and Decision Making, and the European Association of Experimental Society Psychology for their insightful comments and feedback. We gratefully acknowledge the staff at UIBE in Beijing, Jaewook Kim at Korea University, and Tatsuyoshi Saijo at Osaka University for their generous assistance with this research. The second author's research was supported by the National Science Foundation (SES\# 98-76079-001). We also thank several AJS reviewers for their helpful comments. Direct correspondence to Nancy R. Buchan, School of Business, University of Wisconsin, Madison, Wisconsin 53706.
}

(C) 2002 by The University of Chicago. All rights reserved.

0002-9602/2002/10801-0005\$10.00

168 AJS Volume 108 Number 1 (July 2002): 168-206 
Indeed, the growing literature on trust across academic fields focuses on its centrality to every area of our lives. Sociologists and psychologists maintain that trust plays a prominent role in the emergence of cooperation in social dilemmas (Dawes 1980; Messick and Brewer 1983; Coleman 1990) and serves to increase the potential of a system for complexity, allowing agency relationships, for example, to emerge (Shapiro 1987). Political scientists have shown that the level of trust in a society influences governmental efficiency (Putnam 1993). Economists demonstrated that a rise in country-level trust increases national economic growth (Knack and Keefer 1997). Finally, Alan Greenspan underscored the critical nature of trust to our economic way of life, "Trust is at the root of any economic system based on mutually beneficial exchange ... if a significant number of people violated the trust upon which our interactions are based, our economy would be swamped into immobility" (1999).

Trust figures so prominently in myriad social and economic interactions because many of these exchanges resemble "social traps," situations in which a behavior that yields immediate individual advantage leads to negative long-term consequences for the self or others (Platt 1973; Messick and Brewer 1983). Hardin's "tragedy of the commons" (1968) is a classic example of this, and Coleman's description of social exchanges, where there is an unavoidable time lag between promise and delivery, demonstrates where a trap might arise (1990). In such a situation, for instance, the "quality of goods or services exchanged may turn out to be less than expected after it is too late to recover" (Macy and Skvoretz 1998, p. 638). If trust is not present in these social traps, exchange is unlikely to occur.

A number of formal and informal mechanisms come into play in these exchanges to temper individual pursuit. Many are jointly negotiated and involve some sort of institutional control, a contract, for example, to serve as protection against exploitative behavior (Hechter 1987). Other transactions occur under the specter of less-formal controls-for example, the "shadow of the future" (Axelrod 1984)—where the threat of retaliation or loss of reputation may be enough to prompt reciprocation.

Yet there are other exchanges that occur anonymously and in isolation-in the absence of such controls, or of the prospect of repeated interaction. Macy and Skvoretz explain, "There is no tougher test of the possibility of cooperation between self-interested actors, or more generally, of self-interest as the basis of social order. . . The problem of transient and anonymous exchange is not only a matter of considerable practical interest; it is also one of the most theoretically compelling social traps. While the incidence of cheating may be higher between strangers than between neighbors, it is obviously not universal. Not all strangers are dishonest, nor are all cultures reluctant to do business with 'outsiders.' Why not?" (1998, p. 639). 


\section{American Journal of Sociology}

Prompted by this question from Macy and Skvoretz, in this research we explore anonymous, one-shot exchanges among "neighbors" and among "strangers" in four countries. Specifically, we push the boundaries of self-interest in an experimental game in which participants may choose to make a risky investment. If an actor chooses to demonstrate trust and make the investment, the target of any potential reciprocation is either the participant himself, a "neighbor" in an experimentally manipulated group, or a "stranger" who is randomly chosen. We examine the influence that cultural orientation-collectivist or individualist-exerts on participants' reluctance "to do business," as the context of the exchange moves from the dyad, to the group, to strangers.

To study these boundaries, we employ and extend the experimental investment game devised by Berg, Dickhaut, and McCabe (1995). The original game represents a one-shot scenario of reciprocal direct exchange (Emerson 1981). (Fig. 1 depicts the basic structure of the direct exchange). In the investment game, two actors-the sender and the responder-are each given an endowment, say $\$ 10$. The sender is told he can send some, all, or none of his endowment to his anonymous partner, the responder. Any money sent is tripled. The responder then chooses how much of her total wealth (her endowment plus the tripled money for a maximum of $\$ 40)$ to return to the sender. She is facing what economists call a dictator game (Forsythe et al. 1994). Any money the responder does not return is hers to keep; she has full control over the pool of money now in front of her. The unique subgame perfect Nash equilibrium for this game is for the responder to return no money, and thus for the sender to send none. ${ }^{2}$ In our experiment, this models direct reciprocal exchange, and we label this the "direct condition."

In sending money, the sender is demonstrating trust. We apply the behavioral definition used in Kollock's investigation of trust (1994), based on the work of Zand (1972) and Deutsch (1962). "An action demonstrates trust if it increases one's vulnerability . . . to another whose behavior is not under one's control. It refers to the conscious regulation of one's dependence on another" (p. 319). In the exchanges in our experiment, an actor who sends money is increasing his vulnerability to another (the responder) whose behavior is not under his control.

In returning money, the responder is demonstrating reciprocity. The responder may follow a policy of "strict reciprocity," of responding im-

${ }^{2}$ To understand the equilibrium, consider the responder's decision in the second stage of the investment game. The responder is to decide how much he wishes to return to the sender, knowing that once his decision is made and any money returned, the game concludes and the sender has no recourse. In such a setting, the responder will likely return no money. Knowing this, in the first state of the investment game, the sender will not send any money. 


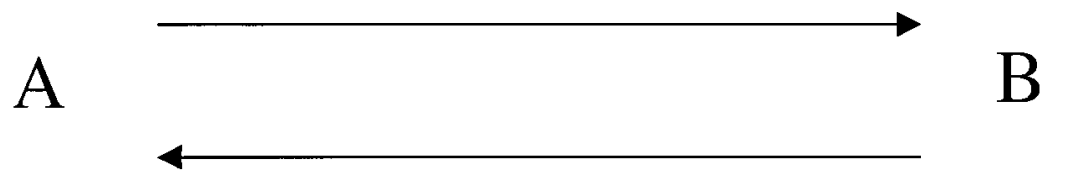

FIG. 1.-Direct reciprocal exchange

mediately and in kind to a partner's behavior (Axelrod 1984). However, following Kollock (1993), given the continuous decision involved in our experiment (i.e., senders or responders may send any amount of money, as compared to the discrete cooperate or defect options seen in prisoners dilemmas), we allow for "relaxed reciprocity" in which any amount returned to the sender is labeled an act of reciprocity. We believe that both the trusting and reciprocal behaviors in this experiment demonstrate forms of cooperative relations, defined by Deutsch as "those in which the goals of the parties involved are predominantly positively interdependent" (2000, p. 25).

To test the boundaries of self-interest, and to look at its relationship to trust and reciprocity, we extend the original investment game by adding two conditions to examine different types of indirect exchange (Molm and Cook 1995). Specifically, we manipulate the social context of exchange within the network-generalized exchange structure (Yamagishi and Cook 1993) depicted in figure 2. In the group condition, the target of potential reciprocation is someone in the sender's (experimentally manipulated) group. The sender likewise is a beneficiary of the potential trust and reciprocation of other members of this "group." In the strangers condition, the target of potential reciprocation is a random participant in the experiment. The sender, likewise, is a beneficiary of the potential trust and reciprocation of another "stranger" in the experiment. The two exchanges are identical in terms of structure and incentives. The sole difference between the two is the presence of experimentally manipulated group identity in the group condition. In both indirect conditions, the equilibrium remains for the responder to return no money and for the sender to send none.

The group and strangers conditions of our experiment build on the generalized exchange research of Yamagishi and Cook (1993). As in the network-generalized exchange structures in Yamagishi and Cook's experiments, in the group and strangers conditions of our experiment, each actor gives to and receives from particular individuals rather than to or from the group as a whole (as would be the case in group-generalized exchange). Furthermore, our games are similarly characterized by a net- 
American Journal of Sociology

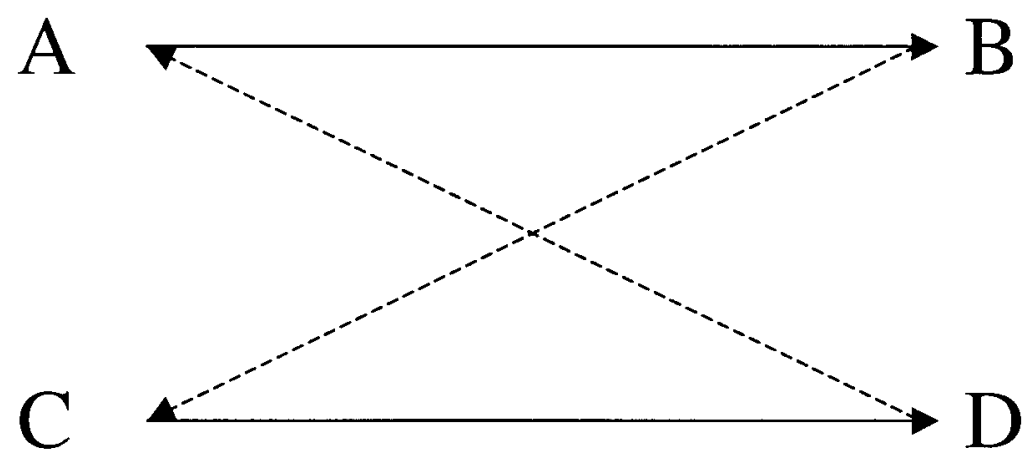

FIG. 2.-Indirect generalized exchange

work of "weak ties" (Granovetter 1973), or unidirectional flows of information, rather than by bidirectional flows. ${ }^{3}$

One fundamental difference between our work and that of Yamagishi and Cook (1993) is in the incentive structure of our networks. First, all four players in the network structure examined in Yamagishi and Cook (1993) faced an incentive structure resembling an $n$-person assurance game (Sen 1967). In the assurance game, if I am assured that the other members will cooperate, it is in my best interest to cooperate as well. ${ }^{4}$ In our experiment, only the sender's behavior is characterized by the assurancegame incentive structure. If the sender believes others in the experiment will cooperate, it is in her best interest to send money; in doing so, value is created for the network, some of which she will capture when the responder reciprocates.

However, the responder is not facing an assurance game, nor is he creating value by his actions, as is the case in a more general social dilemma (Dawes 1980). Rather, the responder, if he chooses to reciprocate, is simply making a transfer from himself to either his own sender (in the direct-exchange treatment), to another sender in his group, or to a stranger. No value is created by this reciprocal action (the money is not multiplied from the responder to the sender); it is simply an opportunity to redistribute the gains from trade previously created by the sender. Thus, when

\footnotetext{
${ }^{3}$ Our exchange structure could be likened to the chain-form of generalized exchange discussed by Bearman (1997). However, the key to that structure is that "all values have to flow through all parties in a cycle before a giver can become a taker, that is, receive a gift in return" (pp. 1389). In our exchange, the values do not flow through all parties, but through pairs in a four-actor structure.

${ }^{4}$ This is in contrast to the $n$-person prisoner's dilemma, where if I believe my partners will cooperate, my payoff is maximized if I defect.
} 
others cooperate, it is not in the responder's best interest to cooperate in turn.

A second fundamental difference in our experiment, and the place where we hope to extend the work of Yamagishi and Cook (1993), is in manipulating the beneficiaries of trust and reciprocation in the network. In doing so, we are addressing what they saw as a need for more comparison of various forms of generalized exchange networks to investigate their implications for the promotion of cooperation and trust. The results of Yamagishi and Cook (1993) demonstrated that "the social structure of some networks ... may make cooperation more likely than in other groups of equivalent size" (p. 246). Our results, using a different networkgeneralized structure than they used, support this as well. In our experiment, two network-generalized exchanges having identical structures and incentives generate different amounts of trusting and reciprocal behavior solely due to manipulated social identity between actors.

In addition to gaining a better understanding of the influence of social structure on cooperation in network-generalized exchange, we also hope to gain an understanding of the influence of culture on the differential treatment of strangers and neighbors, as suggested by Macy and Skvoretz. We demonstrate that cultural orientation significantly influences the ease with which people form groups among experimental strangers and likewise influences the trust and reciprocation extended to these groups.

Finally, we run the experiment in four countries in order to add robustness to our measurement of collectivistic or individualistic culture tendencies. Given the recent proliferation of research discussing the importance of trust to national wealth, economic growth, and governmental efficiency (e.g., Fukuyama 1995; Knack and Keefer 1997; Putnam 1993), demonstrating and explaining how trusting behavior varies from country to country would obviously be of great importance. Yet, upon analyzing the existing nation-based theories of trust, we find that the hypothesized national rankings of trust suggested by these theories contrast with one another, leaving little consensus. Therefore, we regard the national character of this research (as opposed to the cultural one) as exploratory in nature-deepening our understanding of the differences in cooperative behavior that may occur across countries. In doing so, we find that the national results yield interesting theoretical insight into the relationship between trust and reciprocation within each country in the context of one-shot social exchange. 
American Journal of Sociology

THE SELF, STRANGERS, AND NEIGHBORS IN SOCIAL EXCHANGE

Private as well as societal wealth is lost each time an opportunity for productive relationships among society's members is not realized. (Orbell, Zeng, and Mulford 1996, pp. 1030)

Why do exchanges occur at all, and why do some produce more value for participants than others? In this research, we investigate these questions by comparing levels of trusting and reciprocal behavior in different social exchanges, generating four hypotheses. First, we compare levels of cooperation produced in direct versus indirect exchanges (hypotheses 1 and 2). Next, we compare behavior in the indirect exchanges occurring among "neighbors" versus that occurring among "strangers" (hypothesis 3). Finally, we examine how much value is produced across the three types of exchanges and how that value is distributed among the actors in the exchange (hypothesis 4).

First, why would an actor demonstrate trust in a direct-reciprocal exchange, especially given that the structure of such exchange "is inherently fragile because of the potential for actors to receive value without reciprocation" (Molm and Cook 1995)? Furthermore, in the direct condition, as in all conditions in this experiment, the type of trust being demonstrated is "depersonalized trust" (Brewer 1981). That is, these are one-shot, anonymous exchanges in which the participant must respond without any knowledge of the identity of the other exchange participants or of their cooperative tendencies (as might be revealed over a sequence of exchanges; Messick and Brewer 1983). Finally, these exchanges are occurring in the absence of specific information about the partner-"telltale signs of character" (Frank 1988) or "translucent" clues as to the intentions of the partner (Orbell and Dawes 1991) - that would suggest whether extending trust in the exchange is the prudent course of action.

We believe the primary explanation for trusting behavior in direct exchange lies in the rational choice/game theoretic framework (for reviews of this framework, see Dawes [1980], Messick and Brewer [1983], and Yamagishi [1995]). People may be extending trust instrumentally in order to gain other benefits (Takahashi 2000); trusting behavior is based on selfinterested expectations of reciprocation (Williamson 1993).

What happens then to trusting behavior as we move from direct to indirect exchange? In direct exchange, the trusting actor is also the beneficiary of any potential reciprocation. In the indirect conditions in this research, the trusting actor is not the beneficiary of direct reciprocation, but rather any reciprocated amounts will go to someone in the trusters "group" or to a "stranger." Following the logic of rational choice, if the 
chance of receiving direct reciprocation is absent, the motivation to trust is decreased in indirect exchange.

Hypothesis 1.-Trusting behavior will be lower in the indirectexchange conditions than in the direct-exchange condition.

What happens to reciprocal behavior as we move from direct to indirect exchange? Three arguments predict there will be no differences between the direct-exchange and indirect-exchange treatments. A first explanation is the principle of reciprocity. Once an actor takes resources, he is obligated to return them to someone else in the future (Takahashi 2000; Bearman 1997). In fact, Bearman (1997) states "both generalized and restricted (direct) exchange rest on a norm of reciprocity" (p. 1390). This explanation suggests that the norm of reciprocity should not be sensitive to whether any value is returned directly to the sender or whether it is returned to someone else.

A second explanation is suggested by what Yamagishi and Cook (1993) have termed the "diffusion of responsibility." Yamagishi and Cook proposed that cooperation is higher in network-generalized exchange (where actor $\mathrm{A}$ gives to $\mathrm{B}$ who gives to $\mathrm{C}$, and so on) than in group-generalized exchange (where all actors can contribute to and then take from the resource pool), because in the group-generalized exchange structure, participants "will believe that their actions affect each of the other participants less seriously than in the network-generalized exchange structure. ... Participants will feel less responsible for the benefits that each of the other participants receives" (1993, p. 240). In our direct and indirect conditions, the "diffusion of responsibility" is consistent; in all conditions, a participant receives value from an individual and then passes that value on to an individual. Therefore, we expect reciprocation to be constant across all conditions.

The third explanation builds on the previous two. Snijders and Keren (1999) conducted a set of trust experiments to test the proposition that responders reward senders for having taken a risk and entrusting them. They compared reciprocal behavior in an "extensive form" trust game where the sequentiality of the game was explicit (i.e., responder B knew that sender A had entrusted him), with behavior in a "normal form" game in which such sequentiality was not salient. The authors found no difference in reciprocal behavior across the two conditions; responders were not giving greater rewards to specific senders for their trust. These results support the explanation of generalized reciprocity and suggest, like Yamagishi and Cook, that reciprocal behavior will be consistent across our experimental conditions, regardless of the identities of the senders and the potential recipients of reciprocation.

Hypothesis 2a.-Based on the explanations of reciprocity and diffu- 
American Journal of Sociology

sion of responsibility, we expect reciprocal behavior to be invariant across direct and indirect exchanges.

Two other explanations suggest there will be a difference in reciprocity between the direct and indirect exchanges. The first suggests that reciprocation or retribution is based on a desire to reward or punish a partner (Molm 1988; Fehr, Gachter, and Kirchsteiger 1997). This explanation suggests that reciprocation is directly correlated with amounts sent. Furthermore, when moving from direct to indirect conditions, we expect reciprocation to diminish as the ability to reward or punish a trusting or nontrusting partner is removed.

A second explanation preserves the character of Yamagishi and Cook's "diffusion of responsibility" (1993) but refers instead to the target of reciprocation's state of knowledge about the responder's decision. We term this consideration the "ambiguity of responsibility." Experimental evidence from economics suggests that the actor's feeling of responsibility is sensitive to whether the actor believes the responsibility can be fully attributed to him. In these experiments, participants making decisions about how to distribute a pie between themselves and another participant offered less in conditions where the size of the pie was unknown to the other participant, but offered more when the size of the pie was common knowledge (Croson 1996; Kagel, Kim, and Moser 1996). This difference is attributed to fairness concerns that become relevant when the size of the pie is known by all parties.

We believe this influence of asymmetric information could be at work in our experiments as well. In the direct condition, the responder knows that the sender is aware of the value of the exchange (i.e., the size of the pie the responder now can split). In the indirect conditions, by contrast, the responder knows that the potential recipient of reciprocation, whether a member of his group or a stranger, does not know the total value of the exchange (i.e., does not know how much the original sender sent to create the pie). Therefore, a low amount reciprocated could be attributed to either low levels of reciprocity by the responder or to low levels of trust extended by the original sender. It is ambiguous as to whether the responder is not reciprocating or whether he just has a very small pie to slice. Therefore, we expect that as responsibility becomes more ambiguous as we move from the direct- to indirect-exchange conditions, levels of reciprocity will decline.

HypotHesis $2 b$.-Based on the ability to reward or punish a partner and on the "ambiguity of responsibility" involved, we expect reciprocal behavior to be higher in the direct-exchange condition than in the indirect-exchange conditions.

Our discussion now turns to why there may be differences in trusting and reciprocal behavior between the group and strangers' conditions. 
There is abundant evidence to suggest that levels of cooperation are higher among neighbors than among strangers. Economic models show that random interactions within the entire population produce very long convergence times to risk-dominant equilibria, while interactions only among nearest neighbors dramatically shorten convergence (Ellison 1993). The experimental simulation results of Macy and Skvoretz (1998) support this, leading the authors to state that the "earliest trust rule is based on social distance-trust neighbors, but not outsiders" (p. 651).

Experiments in a number of fields have employed the minimal-group paradigm and convincingly demonstrate that even the ad hoc categorization of individuals into mutually exclusive groups is sufficient to create a bias toward one's own group members (an ingroup bias) in intergroup evaluations and allocations (Tajfel and Turner 1979; review articles by Brewer [1979] and Messick and Mackie [1989]). ${ }^{5}$ We will use this minimalgroup paradigm to create neighbors, as opposed to strangers.

The catalyst for ingroup favoritism is the establishment of a sense of group identity (Orbell, van de Kragt, and Dawes 1988; Tyler and Dawes 1993). Group identity is an underpinning to projective reasoning-for example, I believe that if I am a cooperative person and a member of group $\mathrm{X}$, then other members of group $\mathrm{X}$ are likely to be cooperative (Dawes, McTavish, and Shaklee 1977). Based on this, we might expect trusting behavior to be evident in the presence of such reasoning. Note, in suggesting the role of group identity here, we are not doing so to the exclusion of the self-interest paradigm (Macy 1997) nor to the sender's "sense of control" (Hayashi et al. 1999). In extending trust toward a group member, a sender could be demonstrating symbolic or expressive acts on behalf of the group (Lawler, Thye, and Yoon 2000), or he could be sending money because he believes that in doing so he increases the likelihood that a group member will reciprocate. In their discussion of the synthesis between social exchange theory and social identity theory, Lawler, Thye, and Yoon (2000) state that "psychological group formation is a powerful unifying force among a set of independent actors.... Applied to the forms of exchange, productive exchange should be especially conducive to person to group ties" (p. 620).

While Lawler, Thye, and Yoon are discussing the application of psychological group formation to productive exchange (what we have been referring to in this paper as group-generalized exchange) in repeated con-

\footnotetext{
${ }^{5}$ Methods of categorization include distinguishing those who prefer Klee from those who prefer Kandinsky (Tajfel et al. 1971); separating those who underestimate the number of dots on a page from those who overestimate (Tajfel et al. 1971); and placing groups of participants in separate rooms for 10 minutes prior to the intergroup allocation task (Orbell, van de Kragt, and Dawes 1988).
} 
American Journal of Sociology

texts, we propose it will likely have a significant influence in one-shot network-generalized exchanges as well. In the indirect-exchange conditions of our experiment, we analyze the behavior of four-person units (two senders and two responders). In the group-indirect condition, we employ a minimal-group manipulation to engender a sense of group membership among the four actors; in the strangers indirect condition, no such manipulation is implemented.

Hypothesis 3.-Based on previous research demonstrating that cooperation is higher among "neighbors" than among "strangers," we expect trusting and reciprocal behavior to be greater in the group condition of network-generalized exchange in this experiment than in the strangers condition.

Finally we turn to the questions of how much value will be generated in each of the three exchanges, and how will that value be distributed? First, since the total value created in these networks is dependent solely on the trusting behavior displayed (i.e., amounts sent by the senders), we know that if prior hypotheses are true, the value will be greatest in the direct-reciprocal exchange and least in the strangers condition of the network-generalized exchange. Second, the distribution of the value in these exchanges is very much dependent on the balance of power in the exchange. The responder in all three exchanges in this research is the less dependent/more powerful party. As discussed in the section explaining the experiment, the responder has full control over her own endowment plus any money sent (and subsequently tripled) by the sender-hence the label "dictator" by economists (Forsythe et al. 1994). Based on the most basic tenets of power in social exchange in dyads and in networks (Emerson 1962, 1964; Emerson and Cook 1978), we expect responders in all three exchanges to gather a greater share of the value from these exchanges than the sender.

HypотHesis 4.-Because of the imbalance of power in these exchanges, responders in all three conditions will gain a larger share of the value from the exchanges than will senders.

\section{SWIFT NEIGHBORS AND PERSISTENT STRANGERS}

Our final two hypotheses examine how the behavior hypothesized above may be sensitive to the influences of cultural orientation (hypothesis 5) and of country-of-origin (hypothesis 6). First, evidence from cross-cultural research demonstrates significant differences in the process of group formation across cultural types; these differences bear implications for the behavior likely to be seen in our indirect-exchange conditions. Triandis (1995) suggests that a strong correlation exists between cultural orientation 
and the characteristics attributed to closed (constant) membership and open (changing membership) groups (Ziller 1965). Specifically, closed groups, like collectively oriented individuals, tend to "show much reciprocity and are less likely to maximize individual gains by taking advantage of other group members; but people have great difficulties becoming assimilated in such groups" (p. 58). Conversely, people who are individually oriented tend to function like open groups, showing "less reciprocity of action than in closed groups ... they see relationships as transitory ... they are more creative; members can join such groups easily and are easily assimilated" (p. 58).

The difficulty in becoming a member of a collectivist group lies in the fact that collectivist ingroups are few, tend to be more permanent, and are formed on the basis of shared personal characteristics (e.g., family or clan, hometown, or shared school or company affiliation). Among individualists, however, ingroups are more plentiful, tend to be temporary and flexible, and are based on the common beliefs and values of group members (Triandis et al. 1988; Triandis 1995). Triandis concludes, "the greater the rate of change of group membership, the greater the individualism" (1995, p. 58).

Research investigating the minimal-group paradigm has been conducted primarily in individualist cultures (e.g., the United States, Western Europe, etc.; see Hofstede 1980). As discussed, the results of this research have consistently demonstrated an ingroup bias in judgment and allocation decisions.

Research in predominantly collectivist cultures has also demonstrated a strong tendency toward ingroup bias; "collectivists are extremely supportive of ingroups and in situations of conflict treat outgroups very harshly" (Triandis 1995, p. 178). However, this research has been conducted primarily among naturally occurring groups in collectivist cultures, rather than among "minimal" groups that have been experimentally formed for a specific and limited context. ${ }^{6}$

Differences in the process of group formation across the two cultural types suggest that experimentally influenced group biases may not be as evident among collectivist participants as among individualist participants. We propose that collectivist participants will exhibit the same amount of trusting and reciprocal behavior whether they are involved in

\footnotetext{
${ }^{6}$ An example of an exception to this is Yamagishi, Cook, and Watabe (1998), who used artificially created groups to study the free rider problem in Japan and the United States. They suggest that the Japanese participants in their experiment did not act as typical collectivists toward group members because an important element of collective culture did not exist among the artificially created groups (i.e., the group lacked opportunities for mutual monitoring or sanctioning of each others' behavior that might be present in long-term ongoing relationships).
} 
American Journal of Sociology

indirect exchange with experimentally manipulated "neighbors" or "strangers"; experimentally constructed groups are unlikely to foster a perception of a "closed group" for the collectively oriented participant. Individualist participants, on the other hand, will more readily identify and assimilate with their newly formed "neighbors" and will be more cooperative in the group condition than in the strangers condition.

Hypothesis 5.-Based on cultural differences in establishing and defining groups, we expect participants who are relatively more individually oriented to extend greater cooperation in the group indirect exchange than in the strangers indirect exchange. Participants who are relatively more collectively oriented will exhibit constant levels of cooperation across both indirect exchanges.

\section{NATIONAL DIFFERENCES IN TRUST}

How might trust in social exchange differ across countries? Theories of why people from one country may be more trusting than those from another country come from a variety of sources across a number of academic disciplines. Some researchers are more scientific in their approach - with a precise definition and measure of trust and results based on empirical data-others present propositions grounded in theory from disciplines such as cross-cultural psychology, and still others present arguments that are less well supported, but highly provocative. Virtually all of the studies examine trust at a general level, and many use as their measure of trust the question from the World Values Survey "Generally speaking would you say that most people can be trusted or that you can't be too careful in dealing with people?" (Inglehart, Basáñez, and Moreno 1998b).

Table 1 presents a summary of existing research concerning the influence of nationality on trust. Where possible, we also provide the predictions for the current research suggested by these earlier studies.

Together, this previous research provides a varied set of testable predictions of national or institutional-based differences in trust. Indeed, too many differing predictions result. The studies present numerous explanations for differing levels of trust across countries, including the type of culture (Fukuyama 1995) or religion (LaPorta et al. 1997) in a country, the ease of two-way communication within the country (Fishman and Khana 1999), the presence of monitoring or sanctioning mechanisms in a society (Yamagishi 1988b; Hagen and Choe 1998), and the degree and type of associativeness in a society (Putnam 1993). From these studies emerge seven different rankings in general "trustingness" among the countries we examine: China, Japan, South Korea, and the United States. 
Acknowledging the statistical limitations of simultaneously testing multiple theories, we propose a general hypothesis:

Hуротнеsis 6.-Levels of trusting and reciprocal behavior displayed will vary across the four countries studied.

We believe our contribution to this discussion will be to add greater understanding of both trusting and reciprocal behaviors across countries in three specific instances of social exchange. Therefore, although we do not make any hypotheses regarding national differences in reciprocal behavior (since to our knowledge none have been proposed), we also will be testing for national differences in our model of reciprocity and examining the relationship between trusting and reciprocal behavior in each country.

\section{EXPERIMENTAL DESIGN AND PROCEDURES}

In this section, we describe the experimental design and procedures we use to test the hypotheses above. We also explain the controls taken to ensure equivalence in experimental procedure across countries.

\section{Experimental Design}

A total of 548 individuals participated in this experiment: 128 students from the University of International Business and Economics in Beijing, China; 140 students from the University of Korea in Seoul; 140 students from Osaka University in Japan; and 140 students from the University of Wisconsin-Madison in the United States. Participants were primarily sophomore or junior students in economics or business classes who were paid their actual monetary earnings from the experiment.

In each country, we ran three sessions of the experiment, one for each condition. Participants signed up for a session without knowledge of any differentiation in experimental conditions. Once arriving at the experiment, participants were randomly assigned to one of two rooms-the sender room or the responder room.

\section{Experimental Procedure}

The basic procedure for the investment game is as follows. Participants in each room received written instructions for the game, including a diagram of the game structure (figures 3,4 , and 5 below) and a unique subject ID number. The instructions also included a quiz concerning the experimental procedure and the transactions involved, to make certain that all participants understood the task. (All experimental instructions 
TABLE 1

National Differences in Trust

\begin{tabular}{|c|c|c|c|}
\hline Author & $\begin{array}{c}\text { Central } \\
\text { Proposition }\end{array}$ & Definition of Trust & $\begin{array}{c}\text { Evidentiary } \\
\text { Base }\end{array}$ \\
\hline Ouchi 1981 & $\begin{array}{l}\text { Nature of Japanese manage- } \\
\text { ment explains why they } \\
\text { were succeeding economi- } \\
\text { cally where Americans } \\
\text { were not. }\end{array}$ & None provided & $\begin{array}{l}\text { Anecdotal evidence, several } \\
\text { case studies of Japanese } \\
\text { and American companies }\end{array}$ \\
\hline $\begin{array}{l}\text { Yamagishi } \\
\text { et al. } \\
1988 a \\
1988 b \\
1994 \\
1998\end{array}$ & $\begin{array}{l}\text { What has been claimed to } \\
\text { be higher levels of trust } \\
\text { in Japan vs. the United } \\
\text { States is actually a higher } \\
\text { level of assurance about } \\
\text { another's actions. }\end{array}$ & $\begin{array}{l}\text { "An expectation of goodwill } \\
\text { and benign intent" (1994, } \\
\text { p. 131) }\end{array}$ & $\begin{array}{l}\text { Surveys and collective ac- } \\
\text { tion experiments. Depen- } \\
\text { dent variable = trust; ex- } \\
\text { planatory variables = } \\
\text { reputation, uncertainty, } \\
\text { likely use of sanctions }\end{array}$ \\
\hline $\begin{array}{l}\text { Hagen and } \\
\text { Choe } \\
1998\end{array}$ & $\begin{array}{l}\text { Rather than viewing trust } \\
\text { as an inherent force in } \\
\text { Japanese interfirm rela- } \\
\text { tions, institutional and so- } \\
\text { cietal sanctioning mecha- } \\
\text { nisms are responsible for } \\
\text { cooperation. }\end{array}$ & $\begin{array}{l}\text { "The expectation that the } \\
\text { promise of another can be } \\
\text { relied on and that, in un- } \\
\text { foreseen circumstances, the } \\
\text { other will act in a spirit of } \\
\text { cooperation with the trus- } \\
\text { tor" (p. 590) }\end{array}$ & $\begin{array}{l}\text { A detailed account of the } \\
\text { nature and social context } \\
\text { of buyer-seller relation- } \\
\text { ships in Japan }\end{array}$ \\
\hline $\begin{array}{c}\text { Fukuyama } \\
1995\end{array}$ & $\begin{array}{l}\text { Trust is a function of cul- } \\
\text { ture and varies greatly } \\
\text { from one society to an- } \\
\text { other, thus contributing to } \\
\text { differences in the eco- } \\
\text { nomic prosperity of } \\
\text { nations. }\end{array}$ & $\begin{array}{l}\text { "The expectation that arises } \\
\text { within a community of } \\
\text { regular, honest, and coop- } \\
\text { erative behavior, based on } \\
\text { commonly shared norms, } \\
\text { on the part of other mem- } \\
\text { bers of the community" } \\
\text { (p. } 26)\end{array}$ & $\begin{array}{l}\text { Historical and cultural argu- } \\
\text { ments demonstrate the } \\
\text { level of trust in a society }\end{array}$ \\
\hline $\begin{array}{c}\text { Putnam } \\
1993\end{array}$ & $\begin{array}{l}\text { Institutional stability and } \\
\text { economic prosperity are a } \\
\text { function of the level of } \\
\text { social capital (defined as } \\
\text { trust, norms of reciproc- } \\
\text { ity, and associative net- } \\
\text { works) in society. }\end{array}$ & $\begin{array}{l}\text { "You do not trust a person to } \\
\text { do something merely be- } \\
\text { cause he says he will do it. } \\
\text { You trust him only be- } \\
\text { cause, knowing what you } \\
\text { know of his disposition, his } \\
\text { available options and their } \\
\text { consequences, his ability } \\
\text { and so forth you expect } \\
\text { that he will choose to do } \\
\text { it" (p. 171). }\end{array}$ & $\begin{array}{l}\text { 20-year, multimethod analy- } \\
\text { sis of the disparity in eco- } \\
\text { nomic growth and gov- } \\
\text { ernment stability across } \\
\text { regions of Italy; variables } \\
\text { examined = measures of } \\
\text { institutional performance, } \\
\text { trust, cooperation, satis- } \\
\text { faction, civic involvement }\end{array}$ \\
\hline $\begin{array}{c}\text { LaPorta et } \\
\text { al. } 1997\end{array}$ & $\begin{array}{l}\text { Trust enhances economic } \\
\text { performance across coun- } \\
\text { tries. There is a strong } \\
\text { negative correlation be- } \\
\text { tween hierarchical reli- } \\
\text { gions and trust and eco- } \\
\text { nomic performance. }\end{array}$ & None provided & $\begin{array}{l}\text { Two analyses on data from } \\
40 \text { countries: regress eco- } \\
\text { nomic performance mea- } \\
\text { sures on trust and \%pop- } \\
\text { ulation belonging to a } \\
\text { hierarchical religion, and } \\
\text { correlate trust with the } \\
\text { religion }\end{array}$ \\
\hline $\begin{array}{l}\text { Fishman } \\
\text { and } \\
\text { Khanna } \\
1999\end{array}$ & $\begin{array}{l}\text { Trust is not a purely cul- } \\
\text { tural or historic residue, } \\
\text { but can be attributed to } \\
\text { the ease of two-way com- } \\
\text { munication in a society. }\end{array}$ & $\begin{array}{l}\text { "When we say we trust } \\
\text { someone or that someone } \\
\text { is trustworthy, we implic- } \\
\text { itly mean that the proba- } \\
\text { bility that he will perform } \\
\text { an action that is beneficial } \\
\text { is high enough for us to } \\
\text { consider engaging in some } \\
\text { form of cooperation with } \\
\text { him" (p. 80). }\end{array}$ & $\begin{array}{l}\text { Regress level of trust in } 40 \\
\text { countries on the number } \\
\text { of phones per capita, } \\
\text { GDP per capita, \% popu- } \\
\text { lation belonging to hierar- } \\
\text { chical religion, level of } \\
\text { urbanization }\end{array}$ \\
\hline
\end{tabular}

* We made this hypothesis for our research because our experiment does not include any sanctioning mechanism, thus, the constraint on Japanese opportunism is absent.

${ }^{\dagger}$ Fukuyama argues that large-scale businesses emerge in low-trust familistic societies, such as Korea, only when the state creates such corporations through subsidies, guidance, or outright ownership (1995, p. 30). 


\begin{tabular}{|c|c|c|}
\hline Measure of Trust Used & Summary of Main Arguments/Findings & $\begin{array}{l}\text { Trust Prediction for } \\
\text { Current Research }\end{array}$ \\
\hline None provided & $\begin{array}{l}\text { Close relationships between employees and man- } \\
\text { agement in Japanese companies creates trust } \\
\text { that facilitates more efficient and collectively } \\
\text { minded decision making and eases network } \\
\text { realtionships. }\end{array}$ & $\begin{array}{l}\text { Japan }>\text { United } \\
\text { States }\end{array}$ \\
\hline $\begin{array}{l}\text { A six-item general trust scale; } \\
\text { items include "Most people } \\
\text { are basically trustworthy" }\end{array}$ & $\begin{array}{l}\text { Americans display more generalized trust (toward } \\
\text { everyone including strangers). Japanese display } \\
\text { more trust toward ingroup members because of } \\
\text { greater assurance of their actions, as a result of } \\
\text { a system of mutual monitoring and sanctioning } \\
\text { within that society. }\end{array}$ & $\begin{array}{l}\text { United States > } \\
\text { Japan* }\end{array}$ \\
\hline None provided & $\begin{array}{l}\text { Identifies several institutional mechanisms (such } \\
\text { as subcontractor grading, and a dual-vendor } \\
\text { policy) and societal sanctioning mechanisms } \\
\text { (such as ostracism) that promote cooperation } \\
\text { in the buyer- seller relationship. }\end{array}$ & $\begin{array}{c}\text { United States > } \\
\text { Japan* }\end{array}$ \\
\hline None provided & $\begin{array}{l}\text { A correlation exists between trust and the size of a } \\
\text { country's corporations. The low levels of trust } \\
\text { extended outside family circles in China and } \\
\text { Korea, e.g., inhibit the hiring of nonkin profes- } \\
\text { sional managers, and limit the growth of corpo- } \\
\text { rations. High levels of trust in the United } \\
\text { States and Japan are demonstrated by the huge } \\
\text { scale of non-family-run corporations. }\end{array}$ & $\begin{array}{l}\text { United States and } \\
\text { Japan }>\text { S. Korea } \\
\text { and China }\end{array}$ \\
\hline $\begin{array}{l}\text { "Some people say that you usu- } \\
\text { ally can trust people. Others } \\
\text { say that you must be very } \\
\text { wary in your relations with } \\
\text { people. What is your view?" } \\
\text { (p. 112). (Likert scaled } \\
\text { response). }\end{array}$ & $\begin{array}{l}\text { A high degree of civic involvement in society in- } \\
\text { creases trust and thus social capital. Stocks of } \\
\text { social capital are self-reinforcing and cumula- } \\
\text { tive. High levels of social capital correlate } \\
\text { with the most economically prosperous and in- } \\
\text { stitutionally stable regions of Italy. }\end{array}$ & $\begin{array}{l}\text { United States }>\text { S. } \\
\text { Korea }>\text { China }> \\
\text { Japan }^{\ddagger}\end{array}$ \\
\hline $\begin{array}{l}\text { From the World Values Survey } \\
\text { (Inglehart et al.1998a): } \\
\text { "Would you say that most } \\
\text { people can be trusted or that } \\
\text { you can't be too careful in } \\
\text { dealing with people?" (Likert } \\
\text { scaled response). }\end{array}$ & $\begin{array}{l}\text { The correlation between trust and membership } \\
\text { in hierarchical religion is }-0.61 \text {. Holding per } \\
\text { capita income constant, countries with more } \\
\text { dominant hierarchical religions exhibit lower } \\
\text { performance on a number of economic } \\
\text { dimensions. }\end{array}$ & $\begin{array}{l}\text { China }=\text { Japan }> \\
\text { S. Korea > } \\
\text { United States }^{\S}\end{array}$ \\
\hline From the World Values Survey & $\begin{array}{l}\text { The number of phones per capita exerts a strong } \\
\text { positive influence on the level of trust in a so- } \\
\text { ciety. The urbanization phone interaction also } \\
\text { is significant, the link between income and } \\
\text { trust is positive but weak, and \%hierarchical } \\
\text { religion partially mediates the influence of the } \\
\text { number of phones on trust. }\end{array}$ & $\begin{array}{l}\text { United States }>\text { Ja- } \\
\text { pan }>\text { S. Korea }> \\
\text { China }^{8}\end{array}$ \\
\hline
\end{tabular}

* According to data from the World Fact Book (1999), the number of association memberships/capita is the following; China $=.73$, United States $=1.81$, South Korea $=1.34$, Japan $=.45$

$\$$ According to data from the World Fact Book (1999), the \%population belonging to a hierarchical religion is China $=1 \%$, Japan $=1 \%$, Korea $=10 \%$, United States $=28 \%$.

\| This definition is taken from Gambetta (1988). 
American Journal of Sociology

are available from the authors upon request.) Once participants completed the quiz correctly, they were given a numbered envelope containing the experimental money ( $\$ 10$ in the United States and equivalent amounts in other countries). The number on the envelope represented the subject's own identification number.

Senders removed their money from the envelope and replaced in the same envelope any money they wished to send to the responder. Monitors collected the envelopes and took them to the experimenter in a different room who recorded the amount sent, tripled it, and placed the tripled money into different numbered envelopes for delivery by another monitor to the appropriate responder. Notice that this implements a double-blind procedure (Hoffman et al. 1996). The monitor who saw the participant did not know the amount they sent, while the experimenter, who saw the amount sent, did not know the participant. The participants, of course, did not know the identity of their partner. Our experiment was run doubleblind to prevent self-presentation (face-saving) effects, which may be particularly prevalent among Asian participants (Bond and Hwang 1995).

The responders then opened their envelopes and decided how much money to return to the appropriate responder from their own experimental money and the (tripled) money they had received. They placed that amount back into their own envelopes. Monitors collected the envelopes from the responders and gave them to the experimenter who recorded the amounts returned, placed the money back into the senders' original envelopes, and forwarded the envelopes into the senders' room for distribution by the monitors. At this point, the experiment ended. Participants completed a postexperimental questionnaire, were paid their earnings privately, and were dismissed.

\section{Direct Condition}

The direct condition is depicted in figure 3 . This is the most basic condition in the experiment, identical to that of Berg et al. (1995), in which sender A sends some, all, or none of his money to responder B. On the way from sender $\mathrm{A}$ to responder $\mathrm{B}$, the money is tripled by the experimenter. Responder B then has her own experimental money plus triple the money sent by A and can return some, all, or none of her total wealth to A. Aside from explaining the experimental procedure and depicting it on the diagram given to participants, the wording on the instructions specific to this condition is "You will interact with a responder (sender) for purposes of this experiment." 


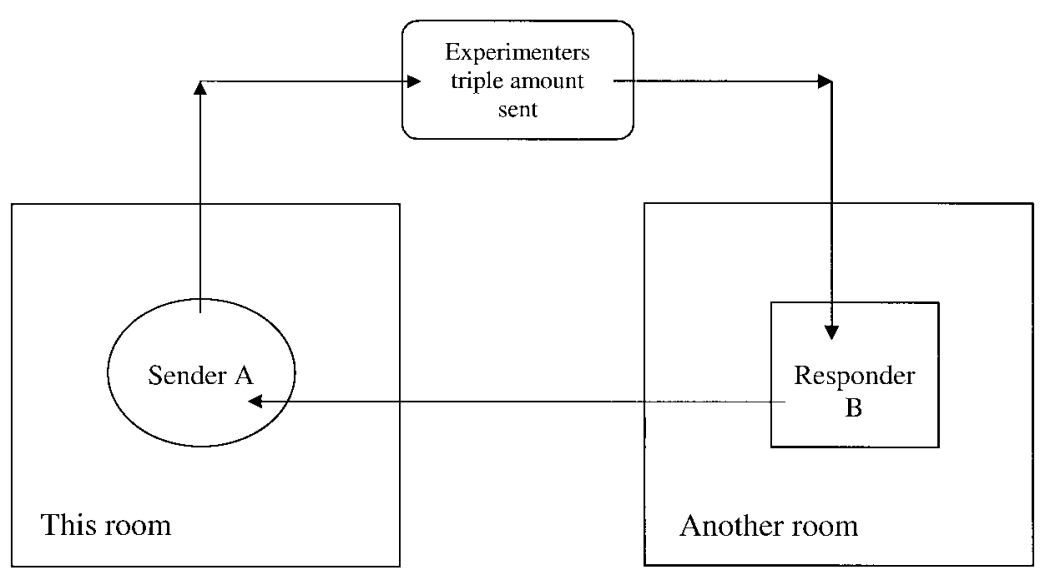

Fig. 3.-Direct condition

\section{Group Condition}

The group condition is depicted in figure 4. In this condition, sender A sends money (which is tripled by the experimenter) to responder B. At the same time, sender $\mathrm{C}$ sends money (which is tripled by the experimenter) to responder D. Responder B then returns some proportion of her wealth to sender C, while responder D returns some proportion of his wealth to sender A. Aside from explaining the experimental procedure and depicting it on the diagram given to participants, the wording on the instructions specific to this condition is "You will interact with three other people for purposes of this experiment." As an additional reinforcement of group identity, each group was given differently colored instructions-thus implementing a standard minimal-group manipulation.

\section{Strangers Condition}

The strangers condition is shown in figure 5. In this condition, sender A sends money (which is tripled by the experimenter) to responder B. At the same time, responder $\mathrm{D}$ receives money from a different, randomly chosen, sender in sender A's room. Responder D then returns some proportion of his wealth to sender $\mathrm{A}$, while responder $\mathrm{B}$ returns some proportion of her wealth to a randomly chosen sender in sender A's room. Aside from explaining the experimental procedure and depicting it on the diagram given to participants, the wording on the instructions specific to this condition is "You will interact with two responders (senders) for purposes of this experiment." 


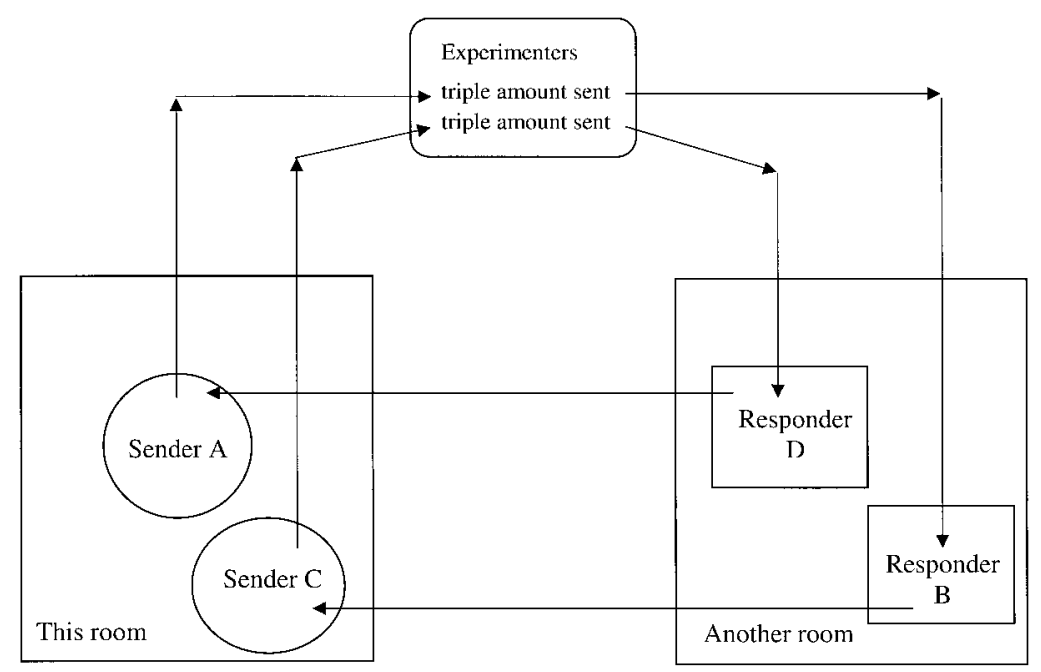

FIG. 4.-Group condition

\section{Cross-Country Controls}

The international character of this research warranted that we control for country or culture-specific variables that could influence our results. Specifically, we addressed the following issues, as suggested by Roth et al. (1991) in their multiple-country investigation of behavior in economic games.

Controlling for subject pool equivalency.-We controlled for equivalency in educational background and knowledge of economics among the subject populations in three ways: First, the universities chosen for the experiment were all well-known universities in their countries. Second, participants were all sophomore or junior economics or business undergraduate students and were paid their earnings in the experiment. Third, participants were questioned about their level of exposure to economic theory and to game theory in particular. Answers to these questions are entered as covariates in the final analysis of results.

Controlling for currency effects.-We controlled for purchasing power parity by choosing denominations such that monetary incentives relative to subject income and living standards were approximately equal across countries (as in Kachelmeier and Shehata [1992]). Amounts used were Japan $(¥ 2,000)$, Korea $(1,000$ won), China (10 yuan), United States $(\$ 10$ dollar). These amounts were based on information from U.S. Bureau of Labor Statistics (U.S. Department of Labor 1998) and on the recommendations of three independent experts on each economy. 
Trust and Reciprocity

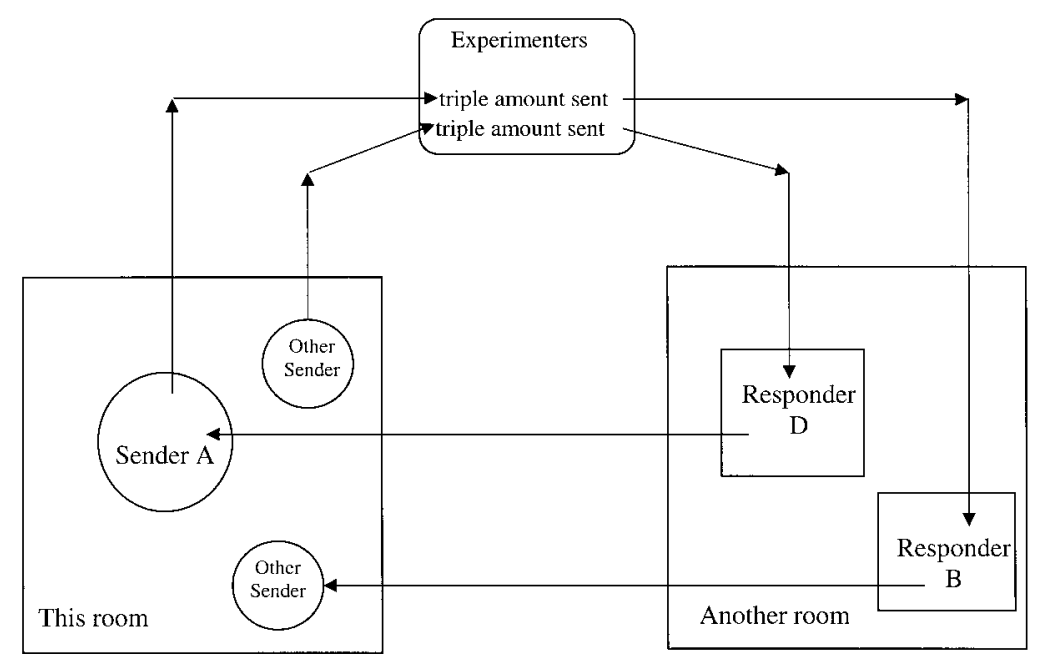

FIG. 5.-Strangers condition

Controlling for language effects.-To control for any nuances in language that may influence results across countries, instructions for the experiments in China, Japan, and Korea were translated into the native language and back-translated into English using separate external translators.

Controlling for experimenter effects.- Various measures were taken to control for differences among experimenters in different countries. First, in each country, the lead experimenter was an advanced student in business and a native of that country. Second, an extremely thorough experimental protocol was designed based upon the procedure used in all four countries. The protocol included information such as the positioning of the experimenter in the room and the method to be used in answering subject questions. Third, the experimenter from the United States met with the lead experimenter in each country prior to each experiment to brief them on the protocol and to run through a practice (no participants) session with them. Finally, the American experimenter was present in the data recording room while each experiment was being conducted.

\section{Experimental Questionnaire}

To assess participants' collectivist and individualist tendencies, we employed the INDCOL scale developed by Singelis et al. (1995). Due to time constraints during the experiment, we shortened the scale to include the 17 questions we believed were the most relevant to our task from the 


\section{American Journal of Sociology}

total 32-item scale. Prior factor analyses have confirmed the cultural dimensions, with reported alpha coefficients for the scales ranging from .68 to $.74 .^{7}$ Questions in the scale were Likert-scaled and included ones such as the following: "One should live one's life independently of others," and "It is important for me to maintain harmony within my group."

To assess the effectiveness of our minimal-group manipulations, we asked participants questions concerning the actors with whom they would be interacting. According to Brewer, intergroup similarity affects "the probability that a respondent will be aware of a relevant basis for categorization into groups, which in turn determines the amount of ingroup bias that is evidenced" (1979, p. 319). Therefore, to tap into participants' perceived similarity, the basic question was, for example, "How similar are you to Responder C? 1 = very different, 7 = very much alike." For the direct-exchange condition, there was a single question concerning the participant's counterpart. For the group indirect-exchange condition, there were three questions concerning the other three members of the participant's group. For the strangers indirect-exchange condition, there were also three questions concerning the two responders or senders with whom the participant was matched and the other senders or responders in their own room. (For the sake of comparability in analysis, the similarity measures for the group and strangers conditions will be the sum of all three similarity responses divided by three). The questionnaire containing the INDCOL scale, the similarity measures, and other questions, such as gender and number of economics classes taken (which will be entered into our analyses as covariates), was administered at the end of the session after participants completed the experimental task.

\section{RESULTS}

\section{Analysis of Questionnaire Measures}

The measures of cultural orientation analyzed with maximum likelihood factor analysis and submitted to oblique rotation (previous research suggests the cultural dimensions are not orthogonal; Singelis et al. 1995). A two-factor structure was obtained, accounting for $12 \%$ of the variance.

\footnotetext{
${ }^{7}$ Use of the INDCOL scale has demonstrated the emergence of four factors: horizontal individualism, horizontal collectivism, vertical individualism, and vertical collectivism (Singelis et al. 1995). A description of these four cultural values is discussed in Triandis (1995). The distinctions between vertical or horizontal individualism and collectivism do not have significant implications for predicted behavior in the exchanges studied here, thus we have collapsed the four dimensions into their two basic forms. For a demonstration of how all four cultural values do influence behavior in social dilemmas, see Probst, Carnevale, and Triandis (1999).
} 
Based on the factor analysis, the items with factor loadings of 0.50 or greater on each factor were selected to measure individualism and collectivism, and the items (six items for collectivism and five for individualism) were summed and averaged, producing two indexes, one for each cultural factor. The Cronbach alphas for each scale were acceptable; 0.70 for the collectivism scale and 0.67 for the individualism scale. ${ }^{8} \mathrm{~A}$ "culture" variable was constructed for future analyses by categorizing participants on the basis of their highest INDCOL score (e.g., Triandis and Gelfand 1998); therefore, "culture" is a 0,1 variable depending on whether the collectivism or individualism score is highest.

Correlations were analyzed between collectivism, individualism, the constructed culture variable, and the four nationalities as indicated by 0,1 dummy variables. The two continuous culture measures are significantly correlated with the culture measure $(r=.54, P<.01$ and $r=$ $-.45, P<.01$, respectively). None of the nationalities are significantly correlated with the constructed culture variable, thus minimizing the multicollinearity in our models when both the culture variable and the countries are introduced. ${ }^{9}$

The similarity measures are intended to serve as manipulation checks on the efficacy of our minimal-group manipulation. The results of an ANOVA on perceived similarity suggest that the manipulation was effective, and as expected, it was more effective among individualist participants. Mean similarity ratings were 4.65 in the direct condition, 4.55 in the group condition, and 3.95 in the strangers condition; the effect is weakly significant $\left(\mathrm{F}_{(2,546)}=2.7, P<.10\right)$. The responses given by partic-

${ }^{8}$ The fact that we administered the scale after the experiment leaves our results vulnerable to the possibility that the experimental procedures themselves may have systematically influenced a preference for one cultural orientation over the other. To investigate this possibility, we conducted a multivariate ANOVA with experimental condition as the independent variable and the cultural measures as the dependent variables. No effects for condition were found, $\mathrm{F}(2,548)=.23$, NS. This result provides a degree of confidence that the culture measure derived reflects an innate orientation of participants, rather than one that was developed and shaped by experimental procedures.

${ }^{9}$ The correlations between culture and each of the nationalities are the following: Chinese $(r=.06, \mathrm{NS})$; Korean $(r=-.05$, NS); Japanese $(r=.02$, NS); American $(r=-.03$, NS). Our results are basically consistent with a just-published meta-analysis of studies that have employed measures of individualism and collectivism (Oyserman, Coon, and Kemmelmeier 2002). For example, the authors conclude, "Researchers should not assume that all East Asians are lower in IND and higher in COL than Americans" (p. 28), after results from the meta-analysis showed Americans to have higher COL scores than Japanese and other Asians (with the exception of participants from China). Additionally, Oyserman, Coon, and Kemmelmeier (2002) show that the degree of collectivism or individualism displayed-and the correlation between the two-depends very much on the focus of the questions used (e.g., duty to ingroup or loyalty to ingroup). 


\section{American Journal of Sociology}

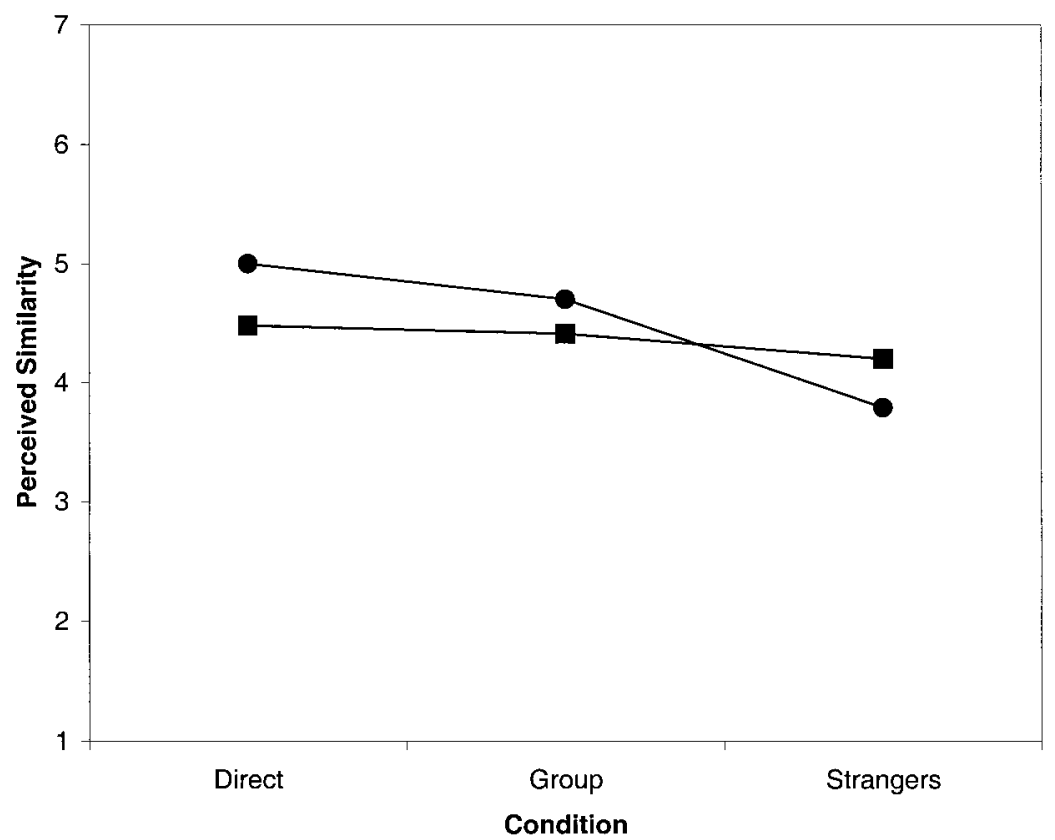

FIG. 6.-Perceived similarity: condition $\times$ cultural orientation; circles $=$ individualists, squares $=$ collectivists.

ipants who were either relatively more collectivist or individualist are shown in figure 6 and demonstrate the significant interaction of culture and condition on similarity ratings $\left(\mathrm{F}_{(2,546)}=4.80, P<.05\right)$. Collectivists perceived the same levels of similarity across all three conditions, while individualists perceived higher levels of similarity in the manipulated group condition than in the strangers condition. Perceived similarity did not significantly differ by role $\left(\mathrm{F}_{(1,546)}=.62, \mathrm{NS}\right)$; senders and responders reacted in the same manner to the experimental social distance.

\section{Experimental Results}

The dependent variables in our analysis are the amount sent by the sender to the responder and the proportion returned by the responder. We calculate the proportion returned as the amount responders returned divided by their total wealth (three times the amount the sender sent plus the endowment). This proportion is the percentage of total wealth that responders are returning to senders in dictator fashion. For purposes of analysis, monetary amounts across the four countries have been standardized on a scale from 0 to 1,000 units. 
Trust and Reciprocity

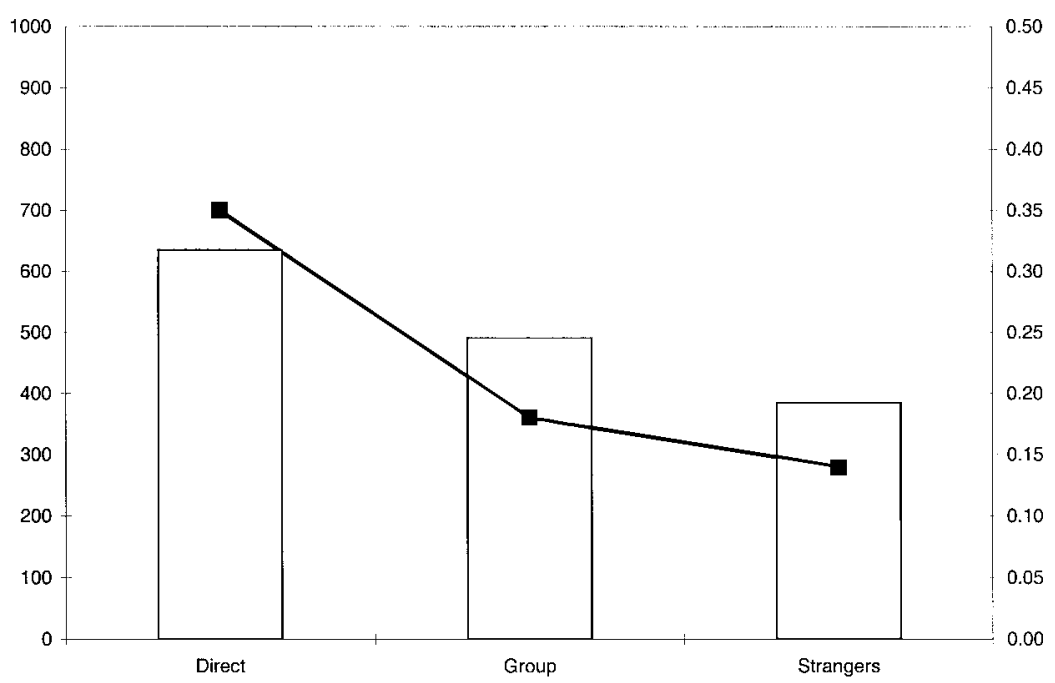

FIG. 7.-Amounts sent and proportions returned across conditions; bars = amount sent, squares $=$ proportion returned.

Figure 7 displays the amounts sent and proportions returned across all conditions of the experiment. Mean amounts sent are 635 in the direct condition, 480 in the group condition, and 387 in the strangers condition. Mean proportions returned equal 0.35 in the direct condition, 0.18 in the group condition, and 0.14 in the strangers condition.

Table 2 shows the results from two analyses of variance. In the first model, the dependent variable is amount sent; in the second model, the dependent variable is proportion returned. In both analyses, the independent variables are experimental condition, the constructed culture variable, and nationality. Additionally, gender and number of economics courses are added as covariates to each analysis, given that such characteristics have been suggested as influences on trusting and reciprocal behavior (Snijders and Keren 2001). Neither covariate, however, proved to have a significant influence on amount sent or proportion returned.

\section{Direct versus Indirect Exchange}

We hypothesized that amounts sent will be lower in the indirect than direct exchange conditions, because in the indirect conditions, the instrumentality of extending trust is missing (hypothesis 1). We proposed contrasting hypotheses for the influence of moving from direct to indirect exchange on proportion returned. If the universal reciprocity argument holds, proportions returned will be invariant across exchange conditions 
American Journal of Sociology

TABLE 2

ANALYSES OF VARIANCE

\begin{tabular}{|c|c|c|}
\hline \multirow[b]{2}{*}{ SOURCE } & \multicolumn{2}{|c|}{ DEPENDENT VARIABLE } \\
\hline & Amount Sent & Proportion Returned \\
\hline Condition $\ldots \ldots \ldots \ldots \ldots \ldots \ldots \ldots$ & $14.38 * * *$ & $12.68 * * *$ \\
\hline Culture $\ldots \ldots \ldots \ldots \ldots \ldots \ldots \ldots \ldots \ldots \ldots$ & 1.76 & $4.62 * *$ \\
\hline Nationality $\ldots \ldots \ldots \ldots \ldots \ldots \ldots \ldots$ & $7.22 * * *$ & $6.12 * * *$ \\
\hline Condition $\times$ culture $\ldots \ldots \ldots \ldots \ldots$ & $4.12 * * *$ & $3.04 *$ \\
\hline Condition $\times$ nationality $\ldots \ldots \ldots \ldots$ & 1.33 & .45 \\
\hline Nationality $\times$ culture $\ldots \ldots \ldots \ldots \ldots$ & 2.11 & .51 \\
\hline Condition $\times$ nationality $\times$ culture $\ldots$ & 1.25 & 1.22 \\
\hline Gender $\ldots \ldots \ldots \ldots \ldots \ldots \ldots \ldots \ldots \ldots$ & 1.18 & .35 \\
\hline 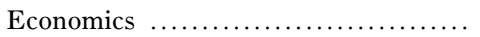 & .92 & .01 \\
\hline$N \quad \ldots \ldots \ldots \ldots$ & 273 & 273 \\
\hline 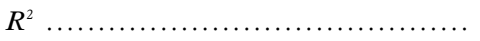 & .25 & .27 \\
\hline
\end{tabular}

(hypothesis 2a). If instead the reward/punishment or ambiguity of responsibility arguments are supported, proportions returned will be lower in the indirect than direct conditions (hypothesis $2 b$ ).

Given that the overall effect of condition is significant for both amounts sent and proportions returned (as shown in table 2), we are able to conduct simple comparisons of the indirect versus direct conditions-collapsing the group and strangers indirect conditions for the contrast. The results of these simple comparisons are highly significant for amount sent $\left(\mathrm{F}_{(1,273)}=26.94, P<.01\right)$, and for proportion returned $\left(\mathrm{F}_{(1,273)}=22.51\right.$, $P<.01)$. Thus, hypotheses 1 and $2 b$ are supported-self-interest seemingly plays a large role in trusting behavior, and reciprocal behavior seems to be motivated by the ability to reward or punish a partner or by the degree to which responsibility for reciprocal acts can be clearly attributed. A generalized norm of reciprocity (which generated hypothesis $2 a$ ) is not supported, as differing proportions of the responders' wealth are returned, depending on whether the reciprocation is going to the sender himself or to someone else.

The fact that responder displayed a high level of reciprocity in the direct generalized exchange condition, but significantly lower amounts in both indirect conditions is also consistent with the ambiguity of responsibility explanation of reciprocity. Responders reciprocated greater proportions of their wealth in the direct exchange where the size of the pie to be shared was common knowledge and responsibility for the value reciprocated was clearly on the shoulders of the responder. Responders reciprocated significantly less in both the indirect exchange conditions 
where the size of the pie was not common knowledge and the responsible party for a low value reciprocated was ambiguous.

\section{Moving from Neighbors to Strangers}

We hypothesized that cooperation will be higher in the group networkgeneralized condition in this experiment than in the strangers networkgeneralized condition (hypothesis 3). Referring to table 2, the effect of condition is highly significant for both amounts sent $\left(\mathrm{F}_{(2,273)}=14.38\right.$, $P<.01)$ and proportion returned $\left(\mathrm{F}_{(2,273)}=12.68, P<.01\right)$. To determine whether amounts sent and proportions returned significantly differ across the group and strangers conditions, we then conducted a Tukey HSD test within the full ANOVA. The difference in mean amounts sent is significant at the $P<.05$ level; the difference in proportions returned across indirect conditions is not significant. Actors in this experiment were more trusting to neighbors than to strangers but were equally reciprocal to both.

We believe this pattern of results suggests a few implications. First, the result concerning reciprocity lends support for the "ambiguity of responsibility" argument since the level of ambiguity was constant across both indirect conditions. Second, the fact that trusting behavior was more influenced by manipulations of social distance than was reciprocal behavior suggests that the influence of group membership may be most powerful when actions are transparent. That is, actions in the interest of the group seem more likely to occur when they will be unambiguous and clearly seen (trusting behavior) than when they will be more ambiguous and not clearly attributable (reciprocal behavior). Finally, the constant level of reciprocity across the indirect conditions does demonstrate that people tend to be trustworthy once others place their trust in them. The amounts returned in these conditions suggest that the prominent issue for the responder may not be social identity, but rather the morality of what to do now that trust has been placed in her.

\section{THE DISTRIBUTION OF WEALTH}

Given that trusting behavior varies significantly across the three conditions, the total amount of wealth generated varies across conditions as well. The maximum wealth in the exchange is 4,000 units; this will be the case if the sender sends all of his 1,000 unit endowment, it is tripled, and the responder adds her 1,000 unit endowment to the 3,000 she receives. Mean amounts of wealth to be divided in each of the conditions are 3,271 ( $82 \%$ of the possible total) in the direct-exchange condition, 
American Journal of Sociology

$2,961(74 \%)$ in the group indirect exchange, and 2,774 (69\%) in the strangers indirect exchange.

Based on the balance of power in these exchanges, we hypothesized that responders will end with a greater proportion of the value from exchange than will senders (hypothesis 4). To test this, we conducted an analysis of variance on final wealth with role and condition as independent variables. While both effects were highly significant, the influence of role was clearly dominant in the model. Our hypothesis was supported concerning the balance of power; senders took home an average of 1,074 units versus 1,873 for the responders $\left(\mathrm{F}_{(1,547)}=160.13, P<.01\right)$.

To gain a deeper understanding of how the trust and reciprocation decisions influenced the wealth of senders and responders in the experiment, we graphed the joint earnings of the players across conditions in the manner done by Berg, Dickhaut, and McCabe (1995) in figures 8, 9, and 10. On these graphs, the large outer triangle with points $\{(0,4,000)$, $(1,000,1,000)$, and $(3,000,1,000)\}$ indicates the set of earnings for the sender and responder pairs in which the responder's final earnings equal at least her endowment. The "no payback line" indicates where $k$ (the amount reciprocated by the responder) $=0$. The "breakeven line" represents the break-even point for the sender, $k=1 / 3(3 \times$ amount sent), and the area to the right of this line indicates positive returns to the sender. The "split total return line" denotes outcomes when the responder evenly splits the amount she received; $k=1 / 2(3 \times$ amount sent $)$. The "split total earnings line" designates when the responder splits total earnings inclusive of her experiment fee; $k=2 / 3(3 \times$ amount sent). Note that points lying below the $(3,000,1,000)$ line represent those pairs where the responder was excessively reciprocal and returned to the sender not only the entire amount received but also a portion of her own endowment.

A regression on the value $k$ with condition as independent variable indicates significant differences across conditions in the wealth distributions between the senders and the responders. A Tukey HSD test comparing $k$ across conditions shows that $k$ is significantly higher in the direct condition $(k=.556)$ than in the group $(k=.369)$ or the strangers $(k=$ $.334)$ conditions $(P<.05)$. Responders are splitting the total experimental earnings almost (but not quite) equally with senders in the direct condition, but in the group and strangers conditions, senders are on average just breaking even. Thus, in each condition, the hypothesis concerning power is supported.

However, these results suggest that although responders may be using their power to their advantage, they certainly are not doing so to the fullest extent. Approximately $13 \%$ of all responders equally shared the total exchange pie with the sender or were even more generous than an equal split. Even in the group and strangers exchange conditions, where 
Trust and Reciprocity

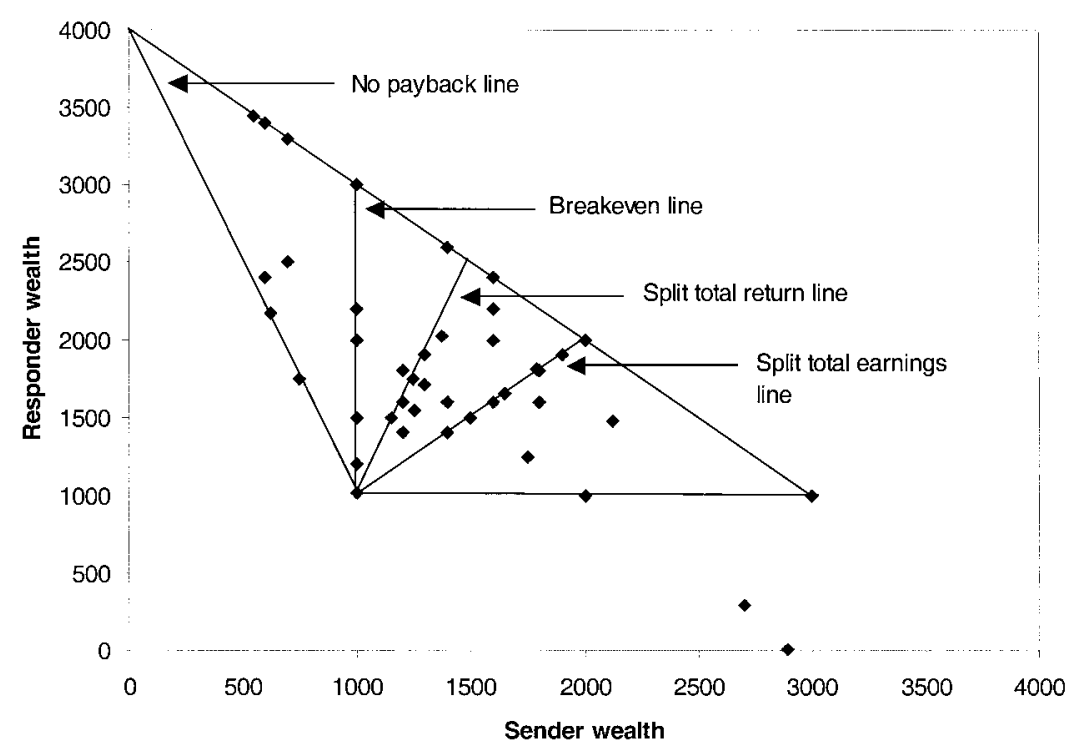

FIG. 8.-Distribution of joint earnings, direct condition

there was "ambiguous responsibility" and the responder could escape full responsibility for her actions, responders do not seem to be getting rich at the expense of the senders; on average, senders went home with their original endowment.

\section{Swift Neighbors and Persistent Strangers}

We hypothesized that differences in the definition and method of group formation would prompt differences across cultural orientations in response to our group and strangers manipulations. The expected outcome is that individualists, who more quickly assimilate with group members, would extend more trust and reciprocation in the group than strangers conditions, but that the behavior of collectivists, who tend not to form quick and temporary groups, would not vary across the two conditions. This hypothesis is supported as shown in table 2. The interaction of condition and culture has a significant influence on amounts sent $\left(\mathrm{F}_{(2,273)}=4.12, P<.05\right)$ and a weakly significant influence on proportions returned $\left(\mathrm{F}_{(2,273)}=3.04, P<.10\right)$. The influence of the interaction on amounts sent is graphed in figure 11. Individually oriented participants seem to quickly embrace "neighbors"-sending relatively equal amounts in the direct and group condition, but less in the strangers exchange, while collectively oriented participants persist in treating all others as 
American Journal of Sociology

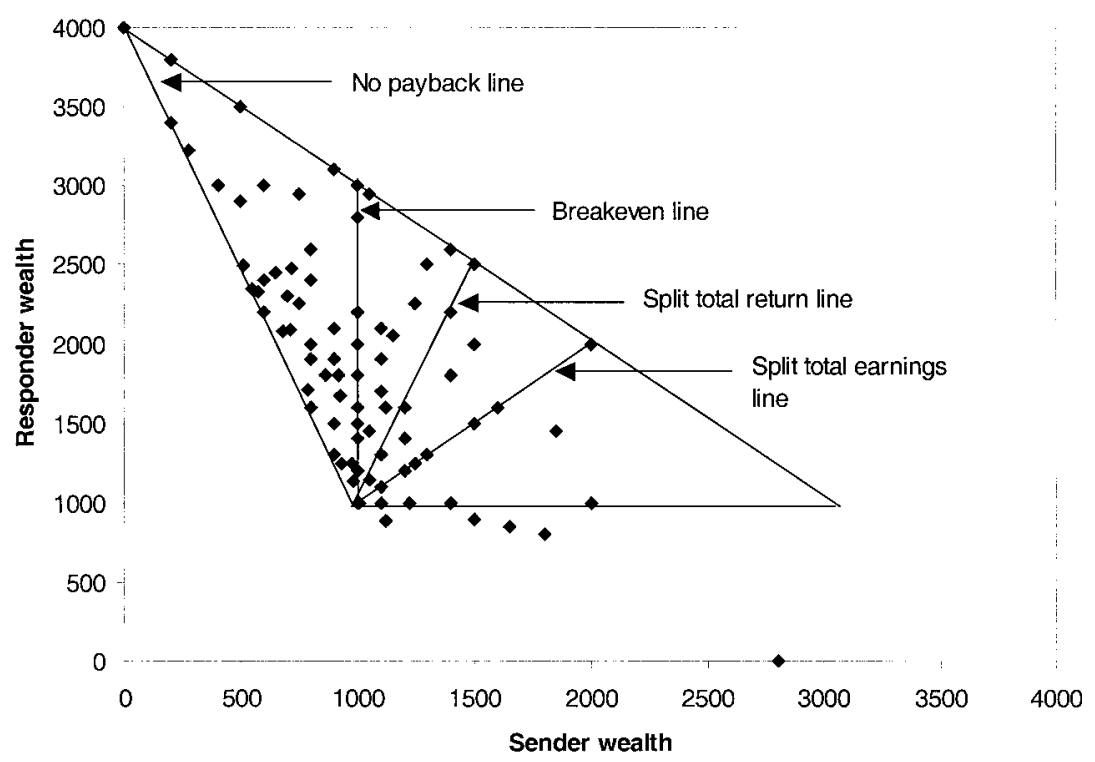

FIG. 9.-Distribution of joint earnings, group condition

"strangers"- extending more trust in the direct condition but less and equal amounts in the group and strangers conditions.

Our results concerning the influence of condition and the condition by culture interaction have been supported; we now turn to trying to gain a better understanding of why. Specifically, is it social identity, as measured here by a similarity measure, which is influencing the changes in behavior across conditions? To test this, we conduct a mediation analysis, as prescribed by Baron and Kenny (1986). First, as shown previously, our manipulation check of the minimal group manipulation demonstrated a significant effect of condition and condition by culture on perceived similarity. Next, the correlation between amount sent and perceived similarity is significant $(R=.15, P<.01)$. However, when perceived similarity is added to the model for amount sent, the influence of the condition or condition by culture variables does not decline. Thus, we conclude, perceived similarity is not a mediating factor on amount sent.

Although we are left without a clear explanation of the interaction between culture and condition, the failure of perceived similarity to mediate the influence of condition on amount sent should not be taken as a lack of support for theories of social identity. Rather, we suspect that the 
Trust and Reciprocity

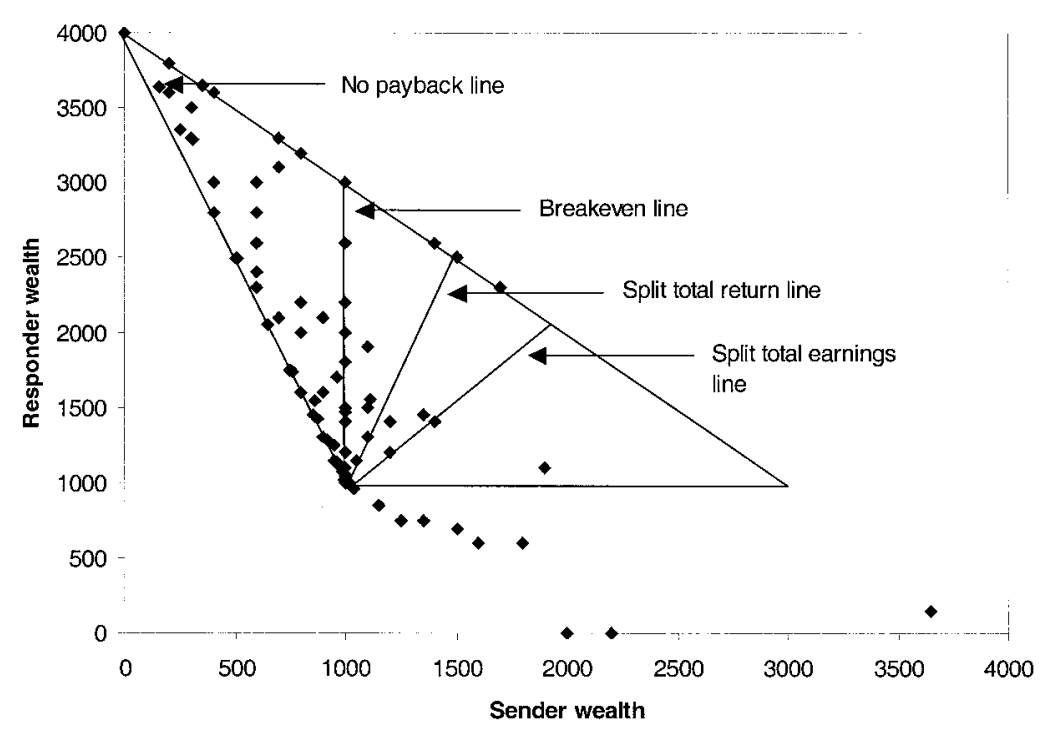

FIG. 10.-Distribution of joint earnings, strangers condition

single measure of perceived similarity used here may not have been broad enough to capture the construct of social identity. ${ }^{10}$

\section{National Differences in Trust}

We hypothesized that national differences in trusting behavior would exist. This hypothesis is supported by our data as shown in the first model of table 2. The influence of nationality is highly significant $\left(\mathrm{F}_{(3,273)}=\right.$ $7.22, P<.01)$ even independent of the effect of culture; and the Tukey HSD test reveals that the amounts sent by American and Chinese participants are significantly higher than amounts sent by Korean and Japanese participants $(P<.05)$. Interestingly, none of the theories listed in table 1 that directly discuss or might be extrapolated to pertain to these four countries (Fukuyama 1995; Putnam 1993; La Porta et al. 1997; Fishman and Khana 1999) provide the ranking of trustingness among China, Japan, Korea, and the United States shown here. The difference in trust extended by American and Japanese participants does, however, support the theories of Yamagishi and colleagues (e.g., 1988a, 1988b, 1994, 1998).

${ }^{10}$ Yamagishi, Jin, and Kiyonari (1999) present an alternative explanation. Their research indicates that the effect of minimal groups is not mediated by identification; rather, it is mediated by the expectation of generalized reciprocity. Future research may tease out these two explanations. 
American Journal of Sociology

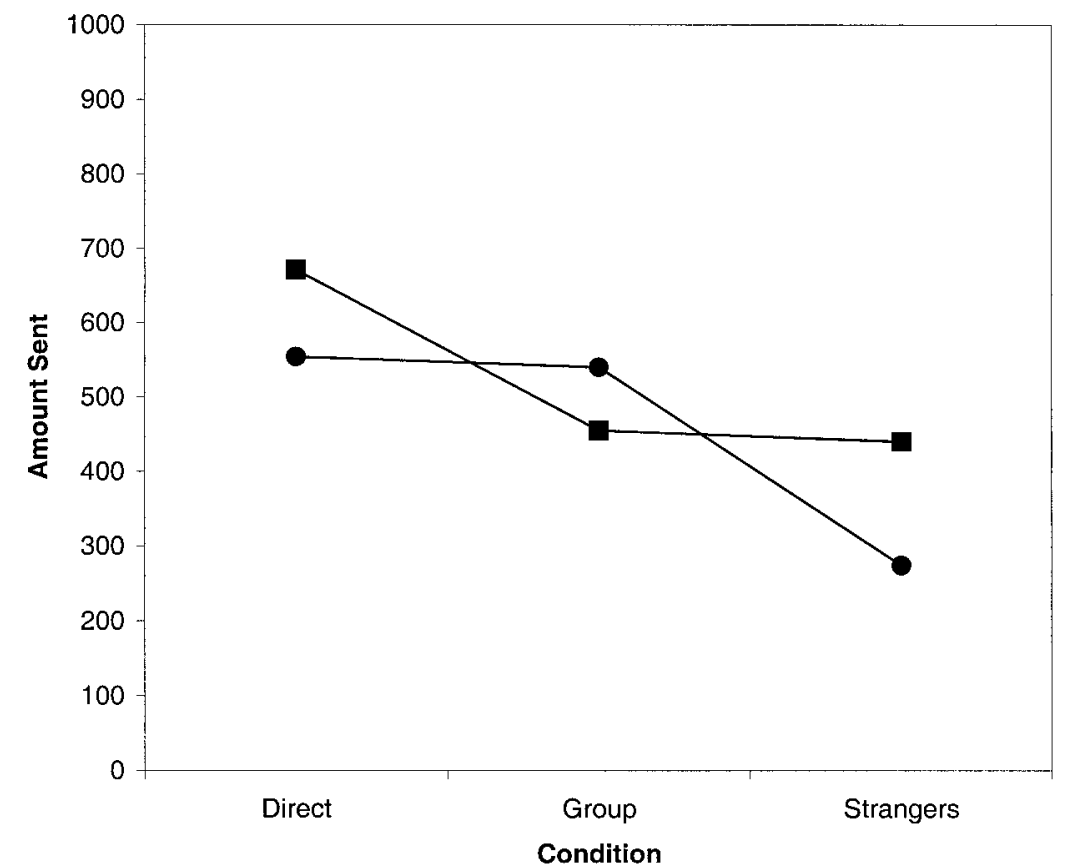

FIG. 11.-Amount sent: condition $\times$ cultural orientation; circles $=$ individualists, squares $=$ collectivists.

Americans have a higher level of general trust and are more trusting than the Japanese in the absence of sanctioning or monitoring mechanisms to influence cooperation.

Although we made no formal hypotheses, we tested for and demonstrate a highly significant influence of nationality of reciprocal behavior as well $\left(\mathrm{F}_{(3,273)}=6.12, P<.01\right)$. The Tukey HSD tests shows that the proportions returned by Chinese and Korean participants are significantly higher than the proportions returned by Japanese and American participants $(P<$ $.05)$. Thus, our results suggest that norms of reciprocity, as well as norms of trust, may vary by country.

The most interesting point in these country comparisons emerges when we compare levels of trusting and reciprocal behavior within each country. We might expect that high levels of trust will be met with high levels of reciprocation and that low levels of trust will be met with low levels of reciprocation. Examination of the relationship between trust and reciprocity across countries reveals some very different patterns (refer to table 3). For simplicity's sake, in this table we define trusters as those who send at least half of their endowment. Reciprocators are defined as 
Trust and Reciprocity

TABLE 3

Trusting and Reciprocal Behavior across Countries

\begin{tabular}{lcc}
\hline \hline & Reciprocators & Nonreciprocators \\
& $($ Sent - Received $>0)$ & (Sent - Received $<0)$ \\
\hline Trusters (sent 500 or more) $\ldots$ & Chinese & Americans \\
& $52 \% / 65 \%$ & $60 \% / 32 \%$ \\
Nontrusters $(\operatorname{sent}<500) \ldots \ldots$ & Koreans & Japanese \\
& $44 \% / 74 \%$ & $44 \% / 34 \%$ \\
\hline
\end{tabular}

NotE. - \%sending 500 or more/\%reciprocating positive amount.

those responders who divided the value of the exchange so that the senders at least broke even (received back at least as much as was sent).

The countries that fit into the rational framework are China and Japan. Chinese participants extend high levels of trust and also high levels of reciprocation; Japanese participants extend low levels of trust and low levels of reciprocation. The relationship between trust and reciprocation becomes confusing when we move to the United States or Korea. American participants show high trust, but relatively low reciprocation. Korean participants demonstrate low levels of trust, but in return receive high levels of reciprocation. ${ }^{11}$

Given that the exchanges in this experiments were one-shot episodes, it is possible that these patterns of trust and behavior will converge after repeated play (Axelrod 1984). (The question of which way they would converge, however, is open to question. Will Koreans become more trusting? Will Americans become more reciprocal?) However, even in these one-shot exchanges, the behaviors exhibited yield insight into the nature of trust and reciprocation. Specifically, trusting and reciprocating may be two very distinct, differently motivated-and sometimes unlinked -cooperative behaviors.

\section{DISCUSSION AND CONCLUSION}

We began this article discussing how trust and reciprocation have been proposed as the "basis of all human systems of morality" (Nowak and Sigmund 2000). We investigated trusting and reciprocal behavior in anonymous, isolated (one-shot) exchanges, situations that represent "no tougher test ... of self interest as the basis of social order" (Macy and Skvoretz

\footnotetext{
${ }^{11}$ Yamagishi in various papers (e.g., Yamagishi, Cook, and Watabe 1998) provides an argument that the portion of trust that is independent of surrounding people's trustworthiness (in our case, the propensity to reciprocate) can be conceptualized as risktaking. This risk propensity may help explain the mismatch between levels of trust and reciprocity.
} 
American Journal of Sociology

1998). Our experiment—in dyads, among group members, and in strangers-demonstrates that self-interest, trust, and reciprocation are all active in social exchange.

A boundary of self-interest seems to lie at the point where direct reciprocity ends. The instrumentality of trust - the expectation of something directly in return-is missing (or, at least, is changed in character) when reciprocity is targeted instead to a group member or to a stranger. Not surprising, amounts sent significantly decrease once the element of direct instrumentality is removed. However, even in the group and strangers exchanges, amounts sent deviate far from equilibrium predictions of no exchange-suggesting that motivations for trust move beyond pure selfinterest. Perhaps the positive amounts sent in the group and strangers conditions are motivated, as suggested by Sabel (1993), by trusting in a shared sense of community with a common fate.

Reciprocity in this experiment seems to be motivated less by reciprocal norms (which suggest that proportions returned would not be influenced by the target of reciprocation), but instead by a motivation to reward or punish a partner or by the ambiguity of responsibility. The finding that levels of reciprocity decrease from the direct condition to lower and equal levels in the indirect conditions suggests that a self-interested responder will keep more and reciprocate less if she knows responsibility for the amount reciprocated cannot be fully attributed to her. Yet, given the balance of power in these exchanges, it is interesting - and downright surprising given the economic equilibrium - that any amounts were reciprocated at all. These findings agree with Rabin (1993), who suggested that the actions of reciprocally motivated individuals produce outcomes that differ significantly from those predicted by models of utility based purely on self-interest.

We demonstrate significant declines in trusting behavior as the context of the exchange moves from the group to strangers. This finding supports the many others that have shown that levels of cooperation tend to be higher the stronger the ties between actors in the exchange (e.g., Granovetter 1973; Orbell, van de Kragt, and Dawes 1988; Macy and Skvoretz 1998). Our results are in agreement with Macy and Skvoretz's (1998) proposition that the first rule of trust is based on social distance. The differential influence of manipulated social distance on trusting and reciprocal behavior suggests, however, that social distance may have its limits. The influence of group membership is likely to be stronger when actions taken can be clearly seen and attributed (trusting behavior) than when they cannot (reciprocal behavior).

The results of Macy and Skvoretz's (1998) repeated simulation also suggests that, if we were to change the character of our exchanges from one-shot to repeated, the "parochial rules" for exchanging within the in- 
group may not survive and greater trust might spread to strangers, giving way to universal solidarity. If this is true, our results concerning cultural orientation and cooperative behavior suggest that the speed at which universal solidarity will be accomplished is likely to vary across cultural types. Participants who were relatively more individually oriented quickly adopted the notion of the group-even an experimentally induced one-and displayed parochialism, demonstrating higher levels of trust toward "neighbors" than toward "strangers." Participants who were relatively more collectively oriented did not embrace the group, but instead persisted in treating all participants in the experiment as strangers-ironically suggesting a relatively longer road to embracing universal solidarity among collectivists than among individualists.

Our national results demonstrate that American and Chinese participants were more trusting in this experiment and that Chinese and Korean participants were more reciprocal. Narrowly interpreted, these findings support the work of Yamagishi and colleagues (e.g., 1988a, 1988b, 1994, 1998), which suggests that levels of cooperation among Japanese participants will be low when monitoring or sanctioning mechanisms are not present to provide assurance of other's cooperative behavior. More broadly interpreted, given the multiplicity of theories concerning the link between country of origin and trust and the contrasting hypotheses and data that result from such research, it is clear that much yet needs to be understood about the influence of national as well as economic, religious, and social factors on trusting behavior.

Furthermore and perhaps more important, many of these nation-based theories, which focus almost exclusively on trust and not on reciprocation, seem to assume that trust and reciprocation go hand-in-hand; when trust is extended, value is created and reciprocated, and society benefits in turn. Our results concerning trust and reciprocation within each country demonstrate that this relationship may be more complex than originally thought. Trust and reciprocation may be delinked, arising out of differing motivations. Further study is needed to more clearly understand the relationship between these two cooperative behaviors and to be able to assess the implications of trust on national prosperity, economic growth, or stability (e.g., Fukuyama 1995; Knack and Keefer 1997; Putnam 1993) when matching levels of reciprocity may not automatically be assumed.

In this experiment, we demonstrated that levels of trust declined when the context of exchange moved from group to strangers, and consequently, the value gained from exchange was reduced. The simulation results of Orbell, Zeng, and Mulford (1996) suggest that fragmentation almost inevitably occurs in society, reducing the opportunities for creation of societal wealth. Like the distinctions made by the minimal-group manipulation in our experiment, Orbell, Zeng, and Mulford show that 


\section{American Journal of Sociology}

fragmentation can occur even in the absence of conflicts of interest or of "statistical" differences between categories or groups of people. Thus, Orbell and colleagues suggest society hangs somewhere in the balance between "full integration," where all encounters result in productive exchange, and a Hobbesian anomic society, in which "nobody consummates play with anybody" (p. 1020).

The introduction of group and stranger distinctions in our experiment influenced the levels of cooperation extended and pulled our results away from a situation of full integration. Nonetheless, the levels of cooperation displayed in these isolated, one-shot encounters are encouraging-keeping at bay a "nasty, brutish, and short" Hobbesian existence. Across the four countries studied, in the direct-reciprocity condition, 55 of 56 senders demonstrate trust and sent money to the responders. In $71 \%$ of those cases, the senders' trust was positively reciprocated by the responders. That is, in the direct-reciprocity condition, $71 \%$ of senders ended up better off (wealthier) than when they had begun, as a result of their trust and their partner's reciprocation.

Although the value produced by exchange decreased as the context of exchange moved from the dyad to group to strangers, our results show that even in the most socially distant indirect exchange condition, actors could still benefit from individuals' trust. In the strangers condition, 101 of 112 senders were trusting, and $23 \%$ of senders benefited from that trust and were reciprocated with more than they had sent. These results show that people will trust and reciprocate to benefit even anonymous strangers, and as a result, a significant portion of society ends up better off than they were.

\section{REFERENCES}

Axelrod, R. 1984. The Evolution of Cooperation. New York: Basic Books.

Baron, Reuben M., and David A. Kenny. 1986. "The Moderator-Mediator Variable Distinction in Social Psychological Research: Conceptual, Strategic, and Statistical Considerations." Journal of Personality and Social Psychology 51:1173-82.

Bearman, Peter. 1997. "Generalized Exchange." American Journal of Sociology 102: $1383-1415$

Berg, Joyce, John Dickhaut, and Kevin McCabe. 1995. "Trust, Reciprocity, and Social History." Games and Economic Behavior 10:122-42.

Bond, Michael Harris, and Kwang-kuo Hwang. 1995. "The Social Psychology of the Chinese People." Pp. 213-66 in The Psychology of the Chinese People, edited by Michael Harris Bond. Hong Kong: Oxford University Press.

Brewer, Marilynn. 1979. "In-group Bias in the Minimal Intergroup Situation: A Cognitive Motivational Analysis." Psychological Bulletin 86:307-24.

- 1981. "Ethnocentricism and Its Role in Interpersonal Trust." Pp. 345-60 in Scientific Inquiry and the Social Sciences, edited by M. Brewer and B. Collins. San Francisco: Jossey-Bass.

Coleman, James. 1990. Foundations of Social Theory. Cambridge, Mass.: Harvard University Press. 
Crosen, Rachel T. A. 1996. "Information in Ultimatum Games: An Experimental Study." Journal of Economic Behavior and Organization 30:197-212.

Dawes, Robyn M. 1980. "Social Dilemmas." Annual Review of Psychology 31:169-93.

Dawes, Robyn M., Jeanne McTavish, and Harriet Shaklee. 1977. "Behavior, Communication, and Assumptions about Other People's Behavior in a Commons Dilemma Situation." Journal of Personality and Social Psychology 35:1-11.

Deutsch, Morton. 1962. "Cooperation and Trust: Some Theoretical Notes." Pp. 275-318 in Nebraska Symposium on Motivation, edited by M. Jones. Lincoln: University of Nebraska Press.

- 2000. "Cooperation and Competition." Pp. 21-40 in The Handbook of Conflict Resolution, edited by M. Deutsch and P. T. Coleman. San Francisco: Jossey-Bass.

Ellison, Glenn. 1993. "Learning, Local Interaction, and Coordination." Econometrica 61:1047-71.

Emerson, Richard. 1962. "Power-Dependence Relations." American Sociological Review 27:31-41.

_. 1964. "Power-Dependence Relations: Two Experiments." Sociometry 27: 282-98.

- 1981. "Social Exchange Theory.” Pp. 30-65 in Social Psychology: Sociological Perspectives, edited by M. Rosenberg and R. H. Turner. New York: Basic Books.

Emerson, Richard, and Karen S. Cook. 1978. "Power, Equity and Commitment in Exchange Networks." American Sociological Review 43:721-39.

Fehr, Ernst, S. Gachter, and G. Kirchsteiger. 1997. "Reciprocity as a Contract Enforcement Device: Experimental Evidence." Econometrica 65:833-60.

Fishman, Raymond, and Tarun Khana. 1999. "Is Trust a Historical Residue? Information Flows and Trust Levels." Journal of Economic Behavior and Organization 38:79-92.

Forsythe, Robert, Joel L. Horowitz, N. E. Savin, and Martin Sefton. 1994. "Fairness in Simple Bargaining Experiments." Games and Economic Behavior 6:347-69.

Frank R. H. 1988. Passions within Reason. New York: Norton.

Fukuyama, Francis. 1995. Trust: The Social Virtues and the Creation of Prosperity. New York: Free Press.

Gambetta, Diego. 1988. "Can We Trust in Trust?" Pp. 213-37 in Trust: Making and Breaking Cooperative Relations, edited by D. Gambetta. New York: Blackwell.

Granovetter, Mark. 1973. "The Strength of Weak Ties." American Journal of Sociologv $78: 1360-80$.

Greenspan, Alan. 1999. Harvard University Commencement Address.

Hagen, James M., and Soonkyoo Choe. 1998. "Trust in Japanese Interfirm Relations: Institutional Sanctions Matter." Academy of Management Review 23:589-600.

Hardin, G. 1968. "The Tragedy of Commons." Science 162:1243-48.

Hayashi, Nahoko, Elinor Ostrom, James Walker, and Toshio Yamagishi. 1999. "Reciprocity, Trust, and the Sense of Control." Rationalitv and Societv 11:27-46.

Hechter, Michael. 1987. Principles of Group Solidarity. Berkeley and Los Angeles: University of California Press.

Hoffman, Elizabeth, Kevin McCabe, and Vernon L. Smith. 1996. "Social Distance and Other-Regarding Behavior in Dictator Games." American Economic Review 86: 653-60.

Hofstede, Geert. 1980. Culture's Consequences. Beverly Hills, Calif.: Sage.

Inglehart, Ronald, Miguel Basáñez, and Alejandro Moreno. 1998a. Human Values and Beliefs: A Cross Cultural Sourcebook. Ann Arbor: University of Michigan Press.

- 1998b. World Values Survey. Ann Arbor: University of Michigan Press.

Kachelmeier, Steven J., and Mohamed Shehata. 1992. "Culture and Competition: A Laboratory Market Comparison Between China and the West." Journal of Economic Behavior and Organization 14:145-68.

Kagel, John, Chung Kim, and Donald Moser. 1996. "Fairness in Ultimatum Games 


\section{American Journal of Sociology}

with Asymmetric Information and Asymmetric Payoffs." Games and Economic Behavior 13:100-110.

Knack, Stephen, and Philip Keefer. 1997. "Does Social Capital Have An Economic Payoff? A Cross-Country Investigation." Quarterly Journal of Economics 1250-88.

Kollock, Peter. 1993. " 'An Eye for an Eye Leaves Everyone Blind': Cooperation and Accounting Systems.” American Sociological Review 58:768-86.

- 1994. "The Emergence of Exchange Structures: An Experimental Study of Uncertainty, Commitment, and Trust." American Journal of Sociologv 100:313-45.

La Porta, Rafael, Florencio Lopez-de-Salanes, Andrei Shleifer, and Robert Vishny. 1997. "Trust in Large Organizations." American Economic Review Papers and Proceedings 87:333-38.

Lawler, Edward J., Shane Thye, and Jeongkoo Yoon. 2000. "Emotion and Group Cohesion in Productive Exchange." American Journal of Sociology 106:616-57.

Macy, Michael W. 1997. "Identity, Interest and Emergent Rationality." Rationality and Societv 9:427-48.

Macy, Michael W., and John Skvoretz. 1998. "The Evolution of Trust and Cooperation between Strangers: A Computational Model.” American Sociological Review 63: 638-60.

Messick, David, and Marilynn Brewer. 1983. "Solving Social Dilemmas: A Review." Pp. 11-44 in Review of Personality and Social Psychology, edited by L. Wheeler. Beverly Hills, Calif.: Sage.

Messick, David, and Diane Mackie. 1989. "Intergroup Relations." Annual Review of Psychology 40:45-81.

Molm, Linda D. 1988. "The Structure and Use of Power: A Comparison of Reward and Punishment Power." Social Psychology Ouarterly 51:108-22.

Molm, Linda D., and Karen S. Cook. 1995. "Social Exchange and Exchange Networks." Pp. 209-35 in Sociological Perspectives on Social Psychology, edited by K. Cook, G. Fine, and J. S. House. Boston: Allyn \& Bacon.

Nowak, Martin A., and Karl Sigmund. 2000. "Shrewd Investments." Science 288: 819-20.

Orbell, John, and Robyn M. Dawes. 1991. "A 'Cognitive Miser' Theory of Cooperators' Advantage." American Political Science Review 85:515-28.

Orbell, John, Alphons van de Kragt, and Robyn M. Dawes. 1988. "Explaining Discussion-Induced Cooperation." Journal of Personality and Social Psychology 54 (5): 811-19.

Orbell, John, Langche Zeng, and Matthew Mulford. 1996. "Individual Experience and the Fragmentation of Societies." American Sociological Review 61:1018-32.

Ouchi, William. 1981. Theory 2. Reading, Mass.: Addison-Wesley.

Oyserman, Daphna, Heather M. Coon, and Marcud Kemmelmeier. 2002. "Rethinking Individualism and Collectivism: Evaluation of Theoretical Assumptions and MetaAnalyses." Psvchological Bulletin 128:3-72.

Platt, John. 1973. "Social Traps." American Psychologist 28:641-51.

Probst, Tahira, Peter J. Carnevale, and Harry C. Triandis. 1999. "Cultural Values in Intergroup and Single-Group Social Dilemmas." Organizational Behavior and Human Decision Processes. 77:171-91.

Putnam, Robert D. 1993. Making Democracy Work: Civic Traditions in Modern Italy. Princeton, N.J.: Princeton University Press.

Rabin, Matthew. 1993. "Incorporating Fairness into Game Theory and Economics." American Economic Review 5:1281-1302.

Roth, Alvin, Vesna Prasnikar, Masahiro Okuno-fujiwara, and Shmuel Zamir. 1991. "Bargaining and Market Behavior in Jerusalem, Ljubljana, Pittsburgh, and Tokyo: An Experimental Study." American Economic Review 81:1068-95.

Sabel, Charles F. 1993. "Studied Trust: Building New Forms of Cooperation in a 
Volatile Economy." Pp. 104-44 in Explorations in Economic Sociology, edited by R. Swedberg. New York: Russell Sage Foundation.

Sen, Amartya 1967. "Isolation, Assurance and the Social Rate of Discount" Quarterly Journal of Economics 82:112-24.

Singelis, T. M., Harry C. Triandis, D. P. S. Bhawuk, and M. Gelfand. 1995. "Horizontal and Vertical Dimensions of Individualism and Collectivism: A Theoretical and Measurement Refinement." Cross-Cultural Research 29:240-75.

Snijders, Chris, and Gideon Keren. 1999. "Determinants of Trust." Pp. 355-86 in Games and Human Behavior, edited by D. Budescu, I. Erev, and R. Zwick. Mahwah, N.J.: Lawrence Erlbaum Associates.

. 2001. "Do You Trust? Whom You Trust? When Do You Trust?" Pp. 129-60 in Advances in Group Processes, edited by S. Thye, E. Lawler, M. Macy, and H. Walker. New York: Elsevier Science.

Tajfel, Henri, M. Billing, R. Bundy, and C. Flament. 1971. "Social Categorization in Intergroup Behavior." European Journal of Social Psychology 1:149-78.

Tajfel, Henri, and John Turner. 1979. "An Integrative Theory of Intergroup Conflict." Pp. 94-109 in The Social Psychology of Intergroup Relations, edited by W. Austin and S. Worchel. Monterey, Calif.: Brooks/Cole Publishers.

Takahashi, Nobuyuki. 2000. "The Emergence of Generalized Exchange." American Journal of Sociology 105:1105-34.

Triandis, Harry C. 1995. Individualism \& Collectivism. Boulder, Colo.: Westview.

Triandis, Harry C., Robert Bontempo, Mracelo J. Villareal, Masaaki Asai, and Nydia Lucca. 1988. "Individualism and Collectivism: Cross-Cultural perspectives on SelfIngroup Relations." Journal of Personality and Social Psychology 54:323-38.

Triandis, Harry C., and M. Gelfand. 1998. "Convergent Measurement of Horizontal and Vertical Individualism and Collectivism. Journal of Personality and Social Psychology 74:118-28.

Tyler, Tom, and Robyn M. Dawes. 1993. "Fairness in Groups: Comparing the SelfInterest and Social Identity Perspectives.” Pp. 87-108 in Psychological Perspectives on Justice, edited by Barbara Mellers and Jonathan Baron. New York: Cambridge University Press.

U.S. Department of Labor. 1998. Monthly Labor Review. Bureau of Labor Statistics, 43-52.

Williamson, Oliver E. 1993. "Calculativeness, Trust and Economic Organization." Journal of Law and Economics 30:131-45.

Yamagishi, Toshio. 1988a. "Exit from the Group as an Individualistic Solution to the Public Good Problem in the United States and Japan." Journal of Experimental Social Psychology 24:530-42.

. 1988b. "The Provision of a Sanctioning System in the United States and Japan." Social Psychology Ouarterly 51:265-71.

. 1995. "Social Dilemmas." Pp. 311-35 in Sociological Perspectives on Social Psychology, edited by K. S. Cook, G. A. Fine, and J. S. House. Boston: Allyn \& Bacon.

Yamagishi, Toshio, and Karen S. Cook. 1993. "Generalized Exchange and Social Dilemmas." Social Psychology Ouarterly 56:235-48.

Yamagishi, Toshio, Karen S. Cook, and Motoki Watabe. 1998. "Uncertainty, Trust, and Commitment Formation in the United States and Japan." American Journal of Sociology 104:165-94.

Yamagishi, Toshio, Nobuhito Jin, and Toko Kiyonari. 1999. "Bounded Generalized Reciprocity: In-Group Boasting and Ingroup Favoritism." Pp. 161-97 in Advances in Group Processes, edited by S. Thye, M. Macy, H. Walker, and E. Lawler. New York: Elsevier Science.

Yamagishi, Toshio, and M. Yamagishi. 1994. "Trust and Commitment in the United States and Japan." Motivation and Emotion 18:9-66. 


\section{American Journal of Sociology}

Zand, D. E. 1972. "Trust and Managerial Problem Solving." Administrative Science Ouarterly 17:229-39.

Ziller, R. C. 1965. "Toward a Theory of Open and Closed Groups." Psychological Bulletin 64:164-82. 